\title{
White Light Emitting Diode Development for General Illumination Applications
}

\section{Final Report}

Report Period Start Date:

Report Period End Date:

Principal Investigator and Author:

Report Submission Date:

DOE Award Number:

Project Manager:
10/01/01

10/31/04

James Ibbetson

May 2006

DE-FC26-00NT40985

Douglas Gyorke

Cree Santa Barbara Technology Center

340 Storke Road

Goleta CA 93117

(805) 968-9460 


\section{DISCLAIMER}

This report was prepared as an account of work sponsored by an agency of the United States Government. Neither the United States Government nor an agency thereof, nor any of their employees, makes any warranty, express or implied, or assumes any legal liability or responsibility for the accuracy, completeness, or usefulness of any information, apparatus, product, or process disclosed, or represents that its use would not infringe privately owned rights. Reference herein to any specific commercial product, process, or service by trade name, trademark, manufacturer, or otherwise does not necessarily constitute or imply its endorsement, recommendation, or favoring by the United States Government or any agency thereof. The views and opinions expressed herein do not necessarily state or reflect those of the United States Government or any agency thereof. 


\section{Table of Contents}

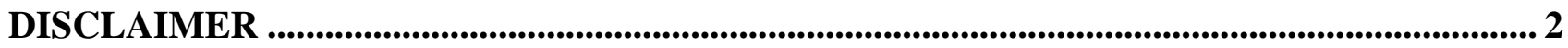

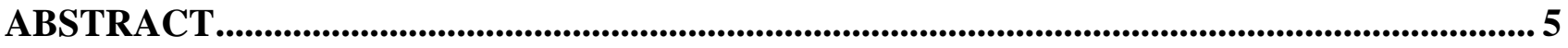

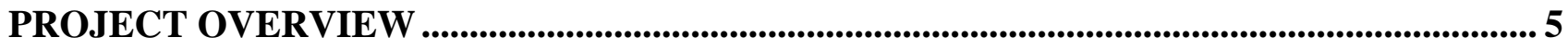

EXECUTIVE SUMMARY OF PROJECT ACHIEVEMENTS ...............................................6

High Power Single Chip LED Advances................................................................... 6

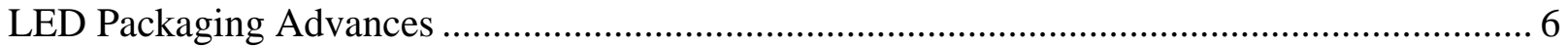

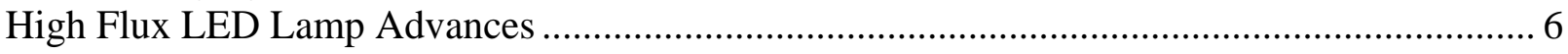

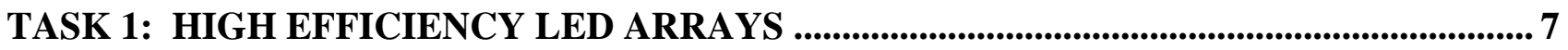

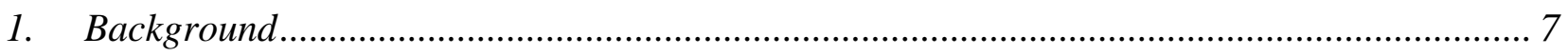

2. Device Materials Development.................................................................................. 7

3. Chip Design - Initial LED Size Scaling................................................................... 8

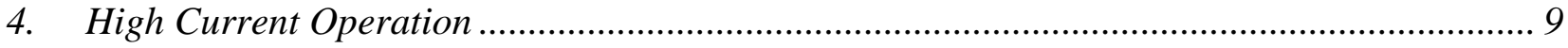

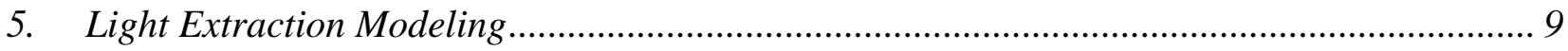

6. Chip Development - Lateral Flip Chip Design.............................................................. 10

7. Chip Development - Improved Light Extraction Via Substrate Modifications ....................... 10

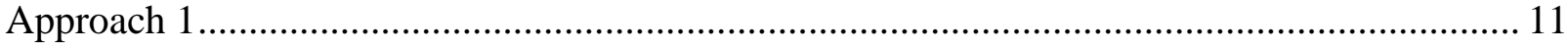

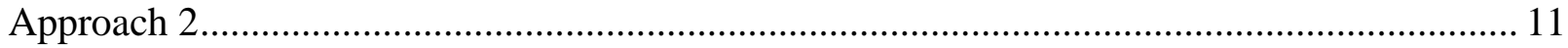

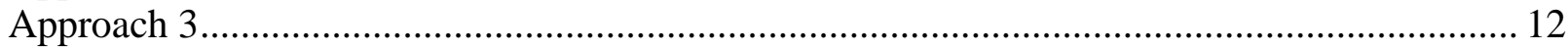

8. Chip Development - High Reflectivity Contacts ............................................................ 12

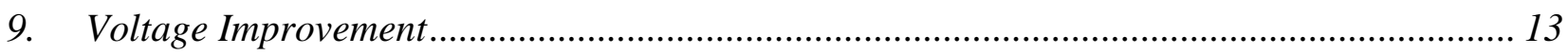

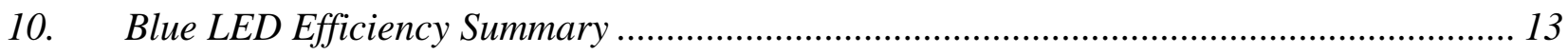

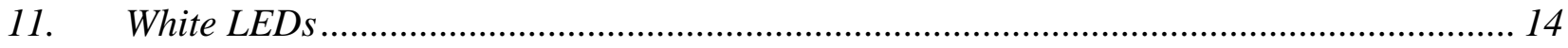

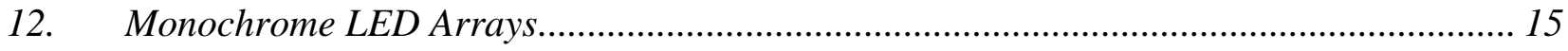

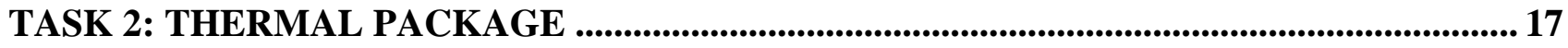

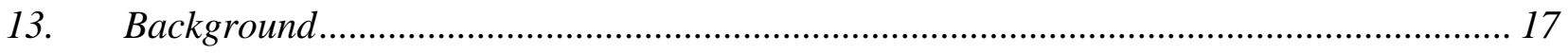

14. Baseline Thermal Characterization Results .................................................................. 17

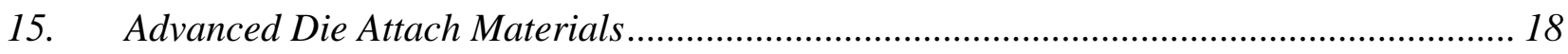

16. Compact LED Module Designs ............................................................................... 19

17. Performance with Multiple Devices Operating .......................................................... 20

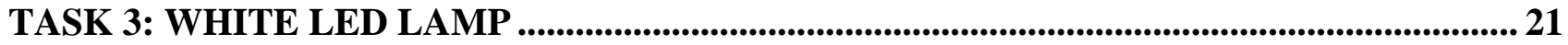




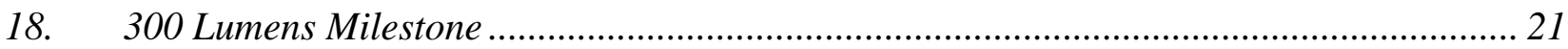

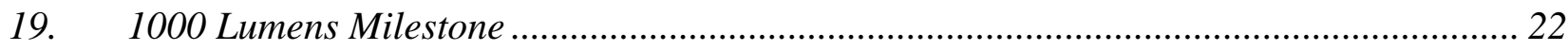

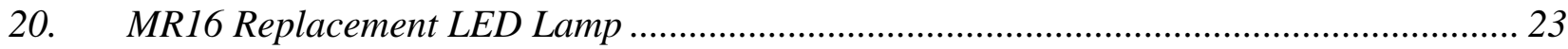

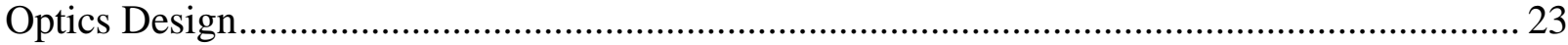

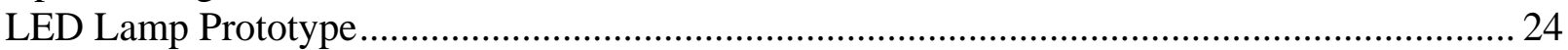

TASK 4: LONG-LIFE 3-WATT LED MODULE ............................................................................ 25

21. High Power White LED Life-Time.......................................................................... 25

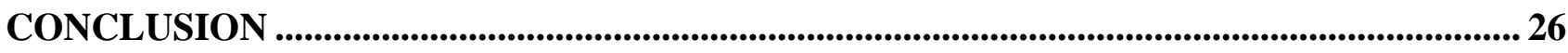

Appendix A: Copy of Press Release Announcing Launch of Power Chip Product..................... 27

Appendix B: Copy of Press Release Announcing 74 lumen per watt R\&D Results.................... 28 


\section{ABSTRACT}

This report contains a summary of technical achievements during a 3-year project aimed at developing the chip and packaging technology necessary to demonstrate efficient, high flux lightemitting diode (LED) arrays using Cree's gallium nitride/silicon carbide (GaN/SiC) LED technology as the starting point. Novel chip designs and fabrication processes are described that led to high power blue LEDs that achieved $310 \mathrm{~mW}$ of light output at $350 \mathrm{~mA}$ drive current, corresponding to quantum and wall plug efficiencies of $32.5 \%$ and $26.5 \%$, respectively. When combined with phosphor, high power white LEDs with luminous output of 67 lumens and efficacy of 57 lumens per watt were also demonstrated. Advances in packaging technology are described that enabled compact, multi-chip white LED lamp modules with 800-1000 lumens output at efficacies of up to 55 lumens per watt. Lamp modules with junction-to-ambient thermal resistance as low as $1.7^{\circ} \mathrm{C} /$ watt have also been demonstrated.

\section{PROJECT OVERVIEW}

The main components of a possible solid-state lamp based on LEDs are shown schematically in Figure 1. The lamp consists of the following components:

1. A primary LED array for converting electrical power to optical power, whose spectrum is typically narrow or monochromatic.

2. A down-converting medium (such as a phosphor) for generation of white light from the primary LED array.

3. A heat sink to dissipate heat generated by the LED array under operation.

4. Optics for re-directing the generated light into a useful flux pattern.

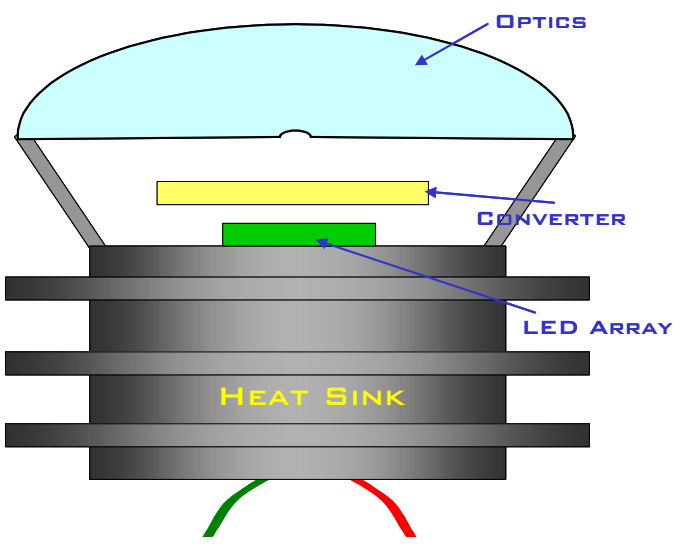

Figure 1

Taking Cree's gallium nitride/silicon carbide blue LED chip technology as the starting point, the focus of the project was aimed at developing the technology required to demonstrate high flux LED arrays by addressing points (1), (3) and (4) above.

Specific task-related milestones for each project period are summarized in Table 1, below. Due to faster than expected progress through Year 2, the original project milestones were met early and additional goals were added after discussions with Department of Energy personnel. The updated goals included the demonstration of a >300 lumen lamp at the end of Year 2; a high power LED module with demonstrated lifetime in excess of 5000 hours; an MR16 lamp prototype; and an endof-project target of a 1000 lumen white lamp with an efficacy of 60 lumens per watt.

\begin{tabular}{|l|c|c|c|}
\hline Task & Year 1 & Year 2 & Year 3 \\
\hline High flux LED Array (watts of optical power) & 4 & 8 & 12 \\
\hline White LED Lamp (luminous flux) & & $>300$ & $>1000$ at 60 Im/W \\
\hline LED MR16 Replacement Prototype & & & Lamp Demo \\
\hline Thermal Package (watts of heat dissipated) & 10 & 15 & 20 \\
\hline Long Life 2-5 Watt Module (hours lifetime) & & & $>5000$ \\
\hline
\end{tabular}




\section{EXECUTIVE SUMMARY OF PROJECT ACHIEVEMENTS}

\section{High Power Single Chip LED Advances}

- Novel chip designs and fabrication processes, together with improved materials work conducted outside the project, resulted in 1-watt class blue GaN/SiC LEDs with world record performance. Blue LEDs operating at $350 \mathrm{~mA}$ achieved 0.310 watts of light output, corresponding to quantum and wall plug efficiencies of $32.5 \%$ and $26.5 \%$, respectively.

- Blue LED performance more than doubled over the course of the project.

- When combined with phosphor to create white light, the improved blue emitters enabled the demonstration of single chip white power LEDs with output of up to 67 lumens and efficacy of up to 57 lumens per watt.

- Cree launched the XBright ${ }^{\mathrm{TM}} 900$ Power Chip LED product family targeting the specialty lighting market. The XB900 chip was initially released in $405 \mathrm{~nm}$ (UV) and $470 \mathrm{~nm}$ (blue) versions and incorporated certain design features developed on this project.

\section{LED Packaging Advances}

- Heat dissipation issue for high power LEDs was addressed through the use of suitable package and chip attach materials.

- High power package concepts and packaging techniques were developed that enabled the demonstration of multi-chip LED modules possessing an overall junction-to-ambient thermal resistance as low as $1.7^{\circ} \mathrm{C} /$ watt when the modules were mounted on a 2-inch square heat sink.

- Optical losses associated with scaling up to multi-chip LED arrays were shown to be largely manageable, with less than $10 \%$ penalty compared to single chip LED lamps demonstrated for a 16-chip module.

- Preliminary results confirmed the promise of very long lifetime lamps based on high power (3-watt input) white LEDs when using appropriate materials in the construction of the LED lamps. Essentially no change was observed in key performance metrics of LEDs operating continuously at a junction temperature of $70{ }^{\circ} \mathrm{C}$ out to 5000 hours.

\section{High Flux LED Lamp Advances}

- A 1000 lumens white lamp module, comparable in output to a 60-watt light bulb, was demonstrated with a luminous efficacy of 55 lumens per watt, or approximately three times that of typical halogen incandescent lamps. Sixteen high performance blue emitters were used as the module's primary light source, together with a phosphor.

- An LED-based MR16 prototype lamp was designed and demonstrated with a narrow viewing angle. Total output of the lamp was 800 lumens, while its efficacy was 40 lumens per watt. Compared to the 1000 lumens lamp module its output and efficacy were reduced, in part due to the additional optics incorporated in the design. 


\section{TASK 1: HIGH EFFICIENCY LED ARRAYS}

\section{Background}

The key to LEDs being useful for solid-state lighting is for them to convert electricity to usable light with very high external quantum efficiency (i.e. photons out per electron in). In essence, the conversion process can be broken down into two components, which are shown schematically in Figure 2. The first is the conversion of electrical energy to optical energy that occurs within an appropriately constructed semiconductor chip. Making this process efficient requires increasing the probability that high-energy free carriers (electrons and holes) injected into the semiconductor recombine radiatively (i.e. generate light) rather than non-radiatively (i.e. generate heat). The second component is light extraction, whereby the generated light or photons 'escape' from the confines of the chip before being re-adsorbed in the semiconductor (the latter being the reverse of the light generation process).

In the first year of the project, both quantum efficiency components were addressed. In Years $2 \& 3$, the technical effort focused almost exclusively on improved light extraction because (a) it was believed to be more critical for meeting the high efficacy goals of the project and (b) the injection efficiency problem could be addressed more effectively by Cree's internal research and

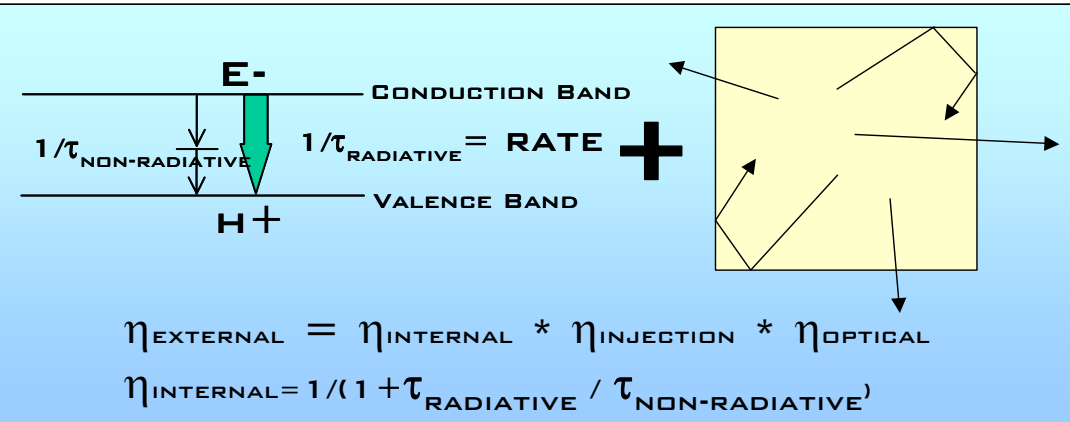

Figure 2. Two components of LED external quantum efficiency development program.

In addition to quantum efficiency, the operating voltage of the LED is also important for overall (wall plug) energy efficiency since excess voltage represents energy that is dissipated (i.e. wasted) as heat. Another area of investigation under Task 1 was therefore directed to improving the LED voltage.

\section{Device Materials Development}

At the start of the project, substantial effort was directed towards understanding and improving the epitaxial growth of gallium nitride (GaN) LEDs on silicon carbide ( $\mathrm{SiC}$ ) substrates. Figure 3 shows a simplified nitride LED structure on $\mathrm{SiC}$ and the critical layers that make up the LED device. Of particular note is the InGaN quantum well layer where the free carrier recombination and photon generation is intended to take place. Extensive studies were made of the various layers to examine the effect of growth conditions and structural parameters on the photon generation process. These studies included such things as varying the layer thicknesses, compositions, growth rates, doping levels, growth temperatures, etc. Various characterization techniques were employed for feedback purposes, including LED fabrication and testing, x-ray diffraction, and surface morphology tools such as atomic force microscopy (AFM) and scanning electron microscopy (SEM).

The aim of the work on this subtask was to improve

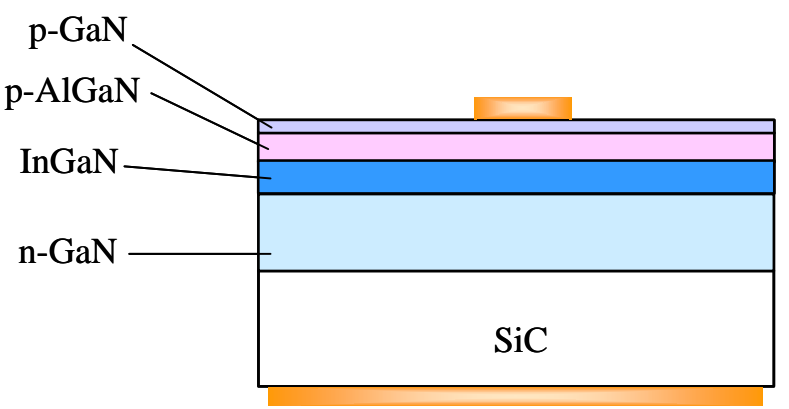

Figure 3. Schematic nitride LED structure 
the baseline LED brightness by reducing the radiative lifetime of free carriers in the InGaN quantum well region, and by reducing the density of defects that contribute to non-radiative recombination processes. For this particular subtask we focused on short wavelength LEDs $(400 \mathrm{~nm})$. As a result of these studies the brightness of $400 \mathrm{~nm}$ LEDs was increased by $50 \%$ from $5.5 \mathrm{~mW}$ to $8.5 \mathrm{~mW}$ at $20 \mathrm{~mA}$ drive current. Subsequent studies performed at Cree (not funded under NETL) further increased the performance to $10 \mathrm{~mW}$. (Note: the numbers quoted in this section correspond to standard baseline cubic LED chips packaged in $5 \mathrm{~mm}$ headers. Significantly higher performance by $2 x$ or more - is possible using the same material and advanced chip processing and packaging.)

\section{Chip Design - Initial LED Size Scaling}

The initial step was to scale-up the physical dimensions of GaN/SiC LEDs to approximately ten times the standard chip area, which was estimated to be the size required for an LED operating in the 1-10 W input power range. A $0.9 \times 0.9 \mathrm{~mm}^{2}$ chip was designed and fabricated using conventional semiconductor processing techniques including metal deposition, photolithography, and etching. After processing, singulated chips were mounted on TO-39 headers, encapsulated with transparent epoxy, and tested in an integrating sphere at $350 \mathrm{~mA}$ drive current.

In the initial demonstration of large area LEDs, an average output flux of $113 \mathrm{~mW}$ was obtained for $470 \mathrm{~nm}$ (blue) LEDs and $165 \mathrm{~mW}$ for $400 \mathrm{~nm}$ (UV) LEDs. These values corresponded to external quantum efficiency (EQE) values of only $12 \%$ and 15\%, respectively. As expected from the performance of standard size chips, the UV LEDs were brighter than the blue LEDs. Also as anticipated, these results showed that the LED efficiency decreased with increasing chip size. Standard size chips fabricated from equivalent material would have yielded LEDs with EQE values of $\sim 18 \%$ and $\sim 22 \%$, respectively. The decrease in efficiency with increasing chip size is due to inherent light extraction effects: as the chip dimensions increase, re-absorption of photons within the semiconductor becomes more problematic.

Over the course of Year 1, several iterations in chip design, fabrication, and characterization were performed in order to improve the light extraction. Table 2 shows the status of LED performance at the end of the year as a combined result of the chip design iteration process and improved materials. Overall, the chip performance was improved by $88 \%$ and $60 \%$ for UV and blue, respectively, as measured by the radiant flux at $350 \mathrm{~mA}$. As a result of this work, some of the design features resulting from the chip optimization performed under the NETL project were incorporated into Cree's first LED power chip product, the XB900"TM, that was announced by Cree in February 2002 (see Appendix A). Figure 4 shows an SEM image of the XB900 chip pictured next to Cree's smaller XB290 ${ }^{\mathrm{TM}}$ chip.

\begin{tabular}{|c|c|c|c|c|}
\hline & \multicolumn{2}{|c|}{$400 \mathrm{~nm}$ (UV) } & \multicolumn{2}{c|}{$470 \mathrm{~nm}$ (Blue) } \\
\hline Date & $5 / 1 / 01$ & $5 / 1 / 02$ & $5 / 1 / 01$ & $5 / 1 / 02$ \\
\hline $\begin{array}{c}\text { Flux } \\
(\mathrm{mW})\end{array}$ & 165 & 310 & 113 & 180 \\
\hline $\begin{array}{c}\mathrm{EQE} \\
(\%)\end{array}$ & 15.2 & 28.9 & 12.2 & 19.5 \\
\hline $\begin{array}{c}\text { WPE } \\
(\%)\end{array}$ & 11.8 & 22.7 & 8.1 & 13.2 \\
\hline
\end{tabular}

Table 2. Performance improvement demonstrated in first generation GaN/SiC power LEDs over the first project year.

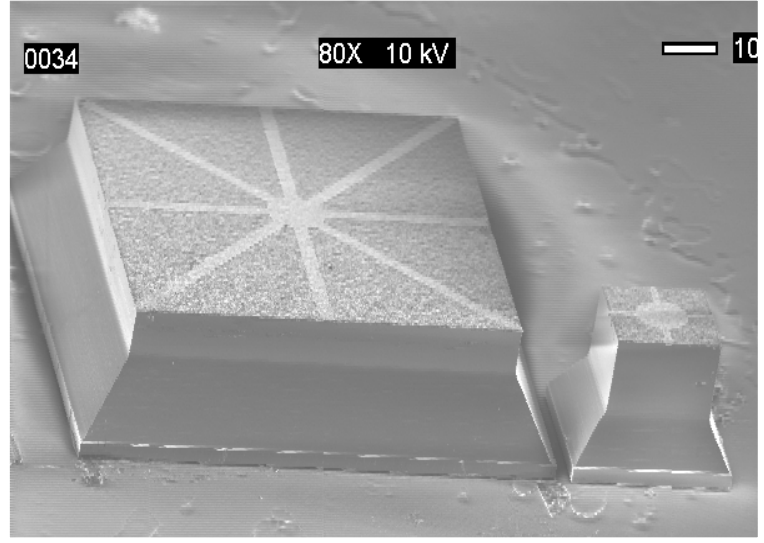

Figure 4 


\section{High Current Operation}

The performance of InGaN LEDs at high current density was also investigated since it is desirable from a cost point of view to use as few LEDs as possible for a given flux. The main outcome of the investigation was to highlight a significant difference in the behavior of blue and UV LEDs. Figure 5 shows representative data for blue and near-UV lamps up to $1.1 \mathrm{~A}$ (approximately three times the standard operating current). These data were measured under pulsed operation to eliminate the effects of self-heating. As shown in the figure, the output power of UV LEDs increases nearly linearly with current compared to a sublinear increase for blue LEDs. At $1 \mathrm{~A}$ drive current, $700 \mathrm{~mW}$ and $370 \mathrm{~mW}$ were measured for UV and blue lamps, respectively.

The nearly linear behavior of the UV lamp out to $\sim 800 \mathrm{~mA}$ can be seen more clearly by looking at the quantum efficiency curve, which was nearly constant. In contrast, there was a significant roll-off in the quantum efficiency of the blue LED starting at 100 $\mathrm{mA}$. The underlying reason for the different behavior is unclear but similar results reported in the literature suggest it may be a

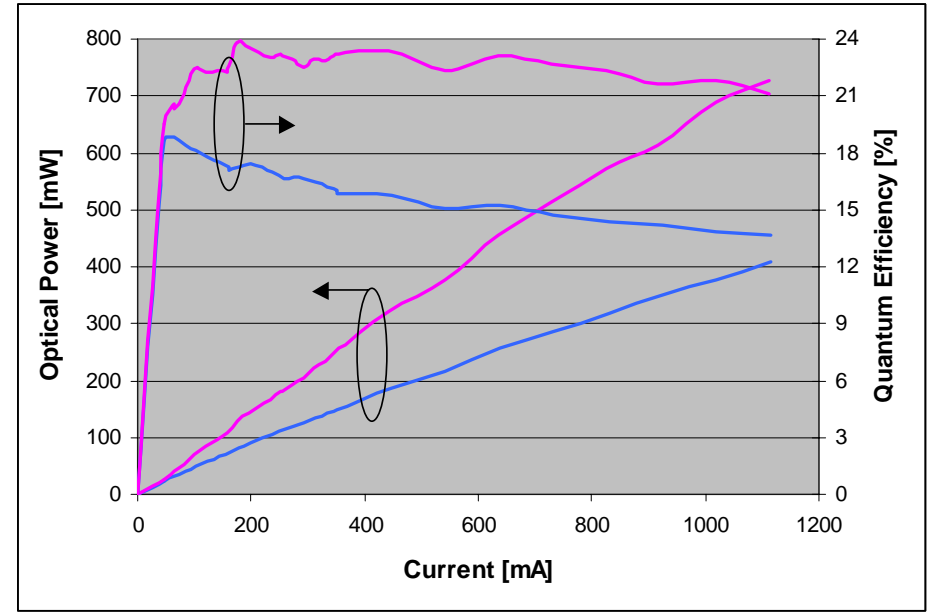

Figure 5: Pulsed optical power and corresponding quantum efficiency as a function of drive current for single-chip, 470nm (blue curves) and 400nm (magenta curves) LED lamps.

fundamental property of InGaN quantum wells. Whatever the cause, the linear high current behavior illustrated a potential advantage of using UV LEDs for solid-state lighting. However, due to a lack of efficient phosphors tuned to excitation by $\sim 400 \mathrm{~nm}$ light, the decision was made at the end of the first year to shift the project's focus thereafter exclusively to $460 \mathrm{~nm}$ (blue) LEDs.

\section{Light Extraction Modeling}

Figure 6 shows schematically the fundamental problem with getting light out of a high index semiconductor (index typically 2.5 - 3.5) into a low index material such as air or epoxy. Light rays inside the high index material refract according to Snell's law upon striking the semiconductor surface. Most importantly, above a critical angle of incidence light rays undergo total internal reflection (TIR) and do not escape. Assuming that the light initially starts in a random direction, for silicon carbide $(\mathrm{SiC}, \mathrm{n}=2.75)$ and gallium nitride $(\mathrm{GaN}, \mathrm{n}=2.5)$ the percentage of light that escapes per surface pass is only $16 \%$ or lower. In other words, $84 \%$ or more of the light is reflected back into the semiconductor where it can be re-adsorbed (i.e. lost to heat).

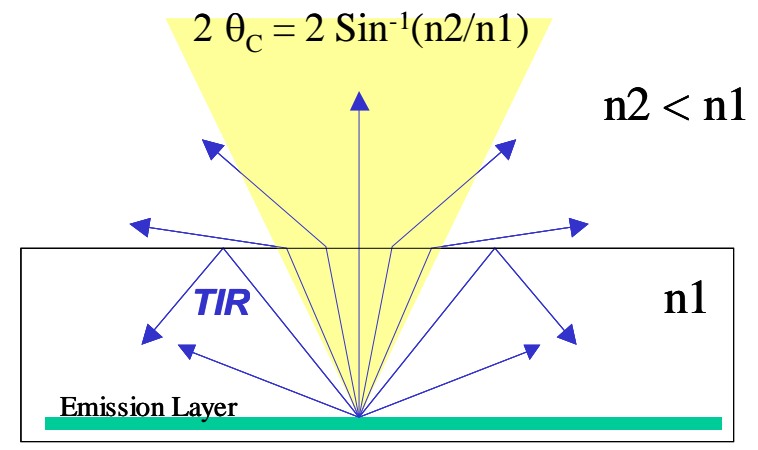

The light extraction problem has long been recognized - it is not unique to nitride LEDs - and a number of strategies have been reported in the technical literature to try to overcome it. Based on Cree's detailed understanding of large area GaN LEDs on SiC substrates, two strategies thought likely to succeed were (a) to modify the SiC substrate surface morphology to maximize its scattering effect on trapped light, and (b) to minimize the optical

Figure 6 

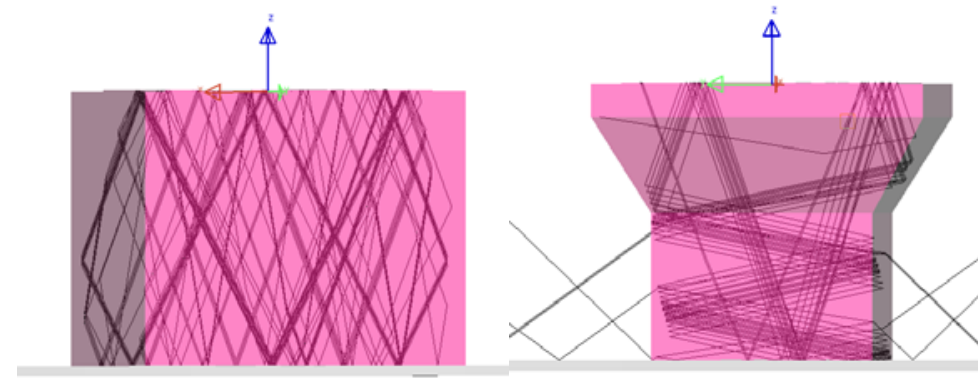

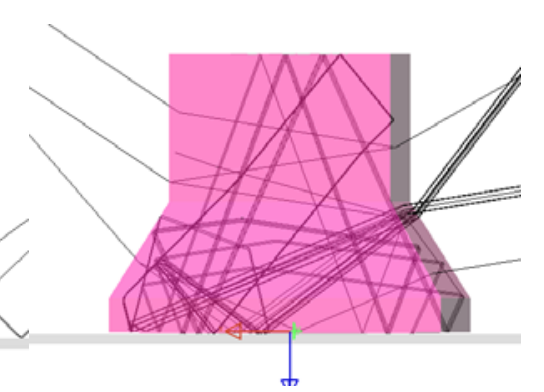

Figure 7. Examples of ray-trace modeling output showing refraction and total internal reflection of light at chip/air interface

losses in the semiconductor, particularly from the partly absorbing metal contacts.

In addition to experimental work, we made extensive use of optical modeling software during the project. The software used was a commercially available ray-tracing program in which a virtual model of our LED chip was created. The model allowed all relevant details of the chip to be included such as, for example, its physical dimensions, the contact metal reflectivity, and materials optical properties. Output of the software included parameters of interest such as total percentage of light escaping from the chip. Thus, the model allowed different chip concepts and modifications to be evaluated relatively quickly and cost-effectively to determine their merits (or lack thereof). Figure 7 shows some simple examples of LED geometries that were modeled.

\section{Chip Development - Lateral Flip Chip Design}

One of the initial tasks during Year 2 was the development of a $0.9 \times 0.9 \mathrm{~mm}^{2}$ lateral flip chip design, shown schematically in Figure 8(a). Unlike a conventional vertical geometry GaN/SiC chip (e.g. Cree's XB900), in the lateral flip chip both diode contacts are placed on the epilayer surface, which are then bonded to a submount chip using, for example, ball grid array technology. The reason for doing this was to allow unfettered access to the SiC substrate surface for subsequent morphology modifications. An interdigitated contact scheme - visible through the transparent $\mathrm{SiC}$ substrate in Figure $\mathbf{8}(\mathbf{b})$ - was included to minimize contact resistance effects. In its base format, the lateral flip chip design was found to be marginally brighter than the equivalent vertical chip design (the XB900). However, the gain came at the cost of a slight increase in operating voltage, resulting in essentially no change to the overall wall plug efficiency.

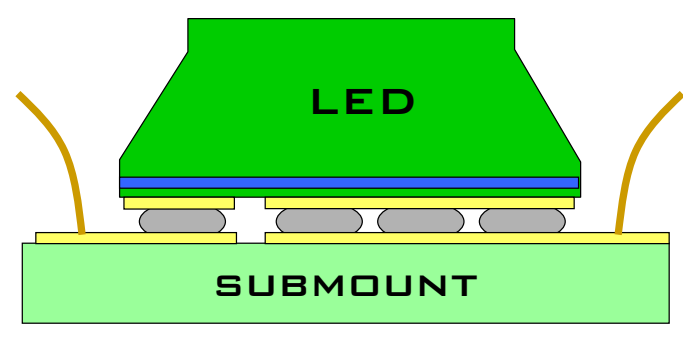

Figure 8(a)

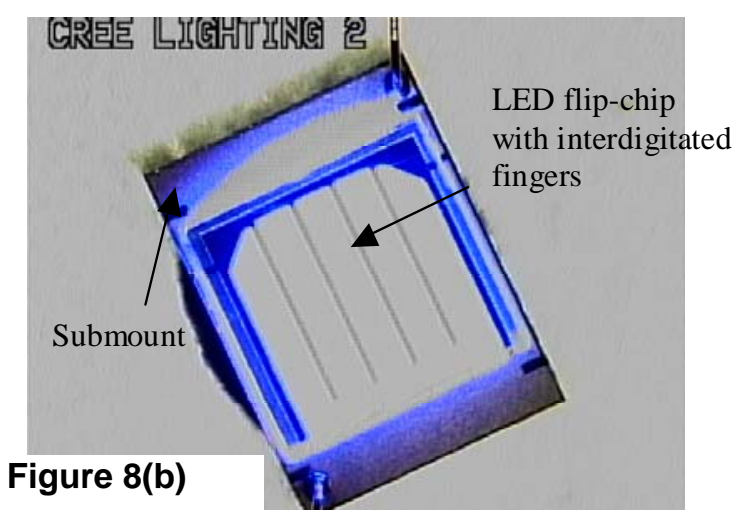

\section{Chip Development - Improved Light Extraction Via Substrate Modifications}

Using the lateral flip chip LED as a test bed, three main approaches for modifying the SiC substrate were investigated and optimized for light extraction during Year 2 and Year 3 of the project. 

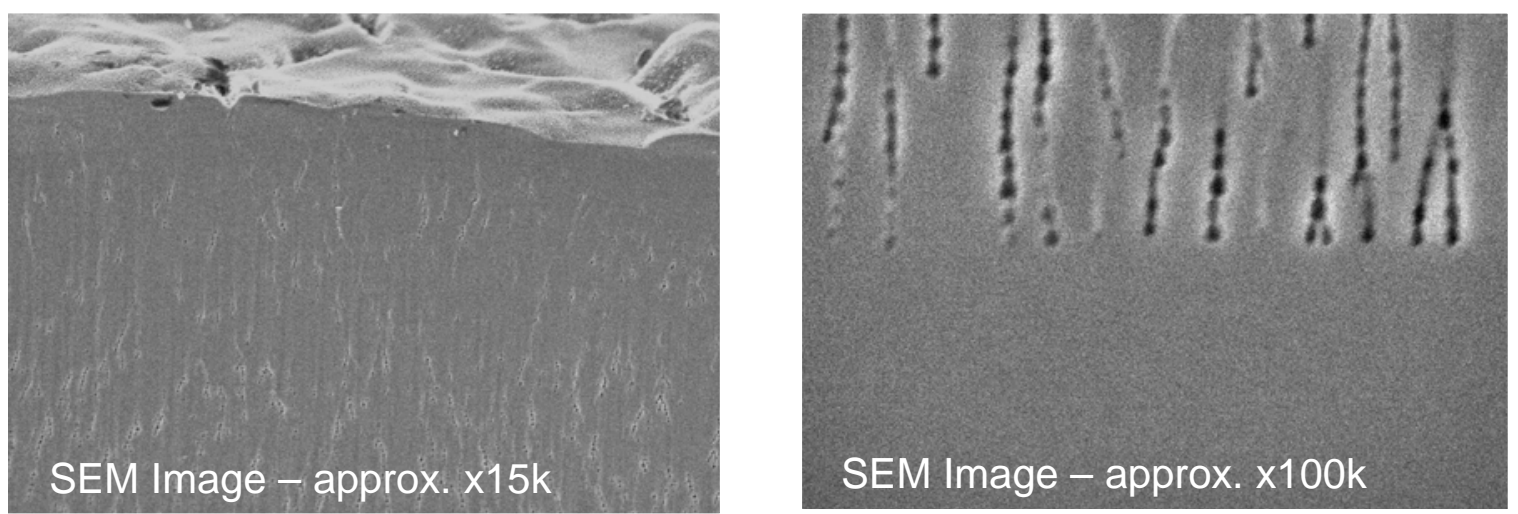

Figure 9

\section{Approach 1}

In the first approach, a novel etching process was developed that created very small $(<<1 \mu \mathrm{m})$ features in $\mathrm{SiC}$, an example of which is shown in the SEM images in Figure 9. The depth (and the width to a lesser degree) of the features could be controlled by the etch parameters and a fairly extensive etch process optimization was conducted during Year 2. LED lamps with this type of SiC surface modification showed an improvement in the quantum efficiency over the reference lamps by as much $13 \%$ due to the photon scattering effect of the etch features.

\section{Approach 2}

In the second approach, chips with large $(>>10 \mu \mathrm{m})$ substrate facets were fabricated. The approach is an extension of the facets that are applied to the perimeter of Cree's high brightness XB900 and XB290 LEDs. Figure 10(a) is a schematic showing the basic concept, with the back surface or substrate of the chip broken up into a number of faceted pillars. The idea is that the many substrate facets provide multiple surfaces through which the light can escape. Optical modeling suggested it might be possible to get $\sim 20 \%$ more light out of a chip with optimal faceting.

Using a lateral flip chip design as the baseline, we fabricated LED chips with various substrate facets and characterized the optical output. A scanning electron micrograph of one example of a chip is shown in Figure 10(b), and an optical microscope image of it under operation in Figure 10(c). By varying the number of substrate facets and their geometric properties (such as angle), we were able to improve the light extraction from unencapsulated chips by as much as $22 \%$ compared to the reference chip with facets around the perimeter only. Thus, the experimental results agreed quite well with the calculations.

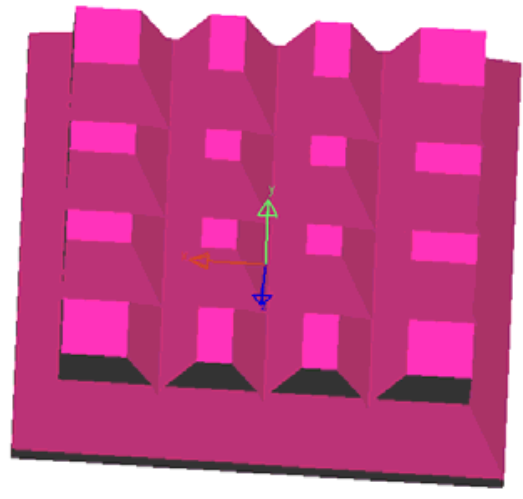

Figure 10(a)

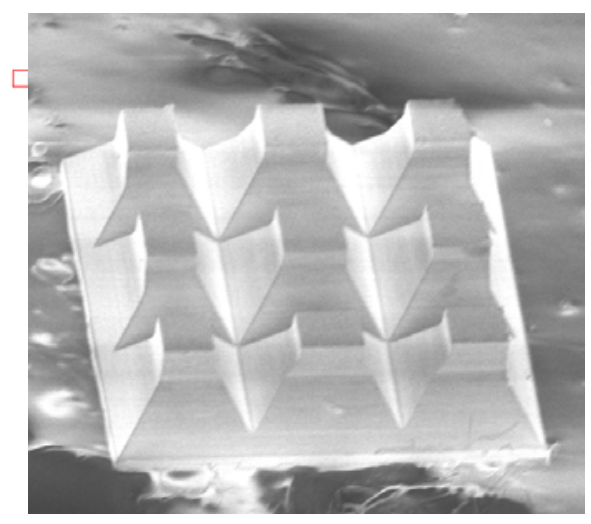

Figure 10(b)

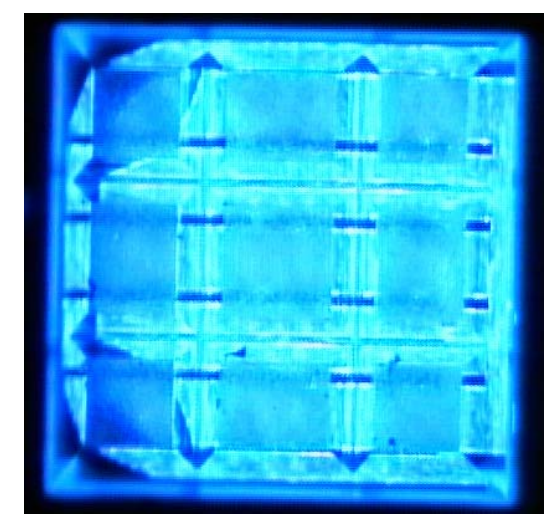

Figure 10(c) 


\section{Approach 3}

In a third approach, another proprietary etch process was developed that created surface features approximately $5 \mu \mathrm{m}$ - $50 \mu \mathrm{m}$ in size. Figure $\mathbf{1 1}$ is an optical microscope image of a SiC substrate with the novel surface finish. The etched surface appears to consist of a random array of approximately circular features. Compared to the first two approaches described above, the morphology is obviously very different in terms of the surface feature size and shape. It was also found that details of the morphology, such as feature size and depth, could be controlled to some degree through the etch process parameters.

A number of LED fabrication runs incorporating this surface modification were completed and light extraction was improved by as much as $15 \%$ over a reference (unetched) sample. Encouragingly, the brightness improvements appeared to correlate with the details of the surface morphology.

In absolute terms, using this particular approach we were able to demonstrate a packaged blue LED operating at 350

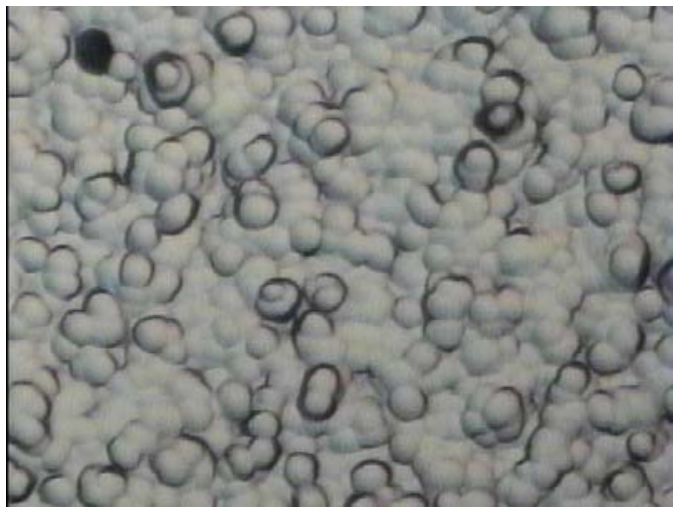

Figure 11 $\mathrm{mA}$ with $280 \mathrm{~mW}$ of optical output power at $464 \mathrm{~nm}$, corresponding to an external quantum efficiency of $29.5 \%$. The operating voltage was 3.36V. At the time these results represented the best performance to date on the project for a 1-watt class blue LED.

\section{Chip Development - High Reflectivity Contacts}

Since the LED chip is a flip-chip design (p-contact and epilayers down), the reflectivity of the pcontact metal has a large impact on the overall chip brightness. Approximately $50 \%$ of the light has to make at least one reflection off this metal surface, in addition to any light that undergoes TIR after failing to escape from the chip on the first pass. Metals with the highest reflectivity are $\mathrm{Al}$ and Ag, which have a reflectivity of $>90 \%$ in the wavelength of interest. Unfortunately, it is relatively difficult to make good ohmic contacts to p-type $\mathrm{GaN}$ and neither $\mathrm{Ag}$ nor Al worked well in this regard. Metals typically used to make good ohmic contacts to p-type $\mathrm{GaN}$ are Pt, $\mathrm{Ni}, \mathrm{Au}$ or $\mathrm{Pd}$, which have a reflectivity of $\sim 60 \%$ or lower. Consequently, a substantial fraction of light was being re-absorbed by the metal contact in the baseline generation of LEDs.

Optical modeling suggested it might be possible to get 20\% more light output using, for instance, Ag instead of the baseline metal scheme. Since Ag by itself did not work well, a number of composite metal contact schemes were evaluated using $\mathrm{Ni}, \mathrm{Au}, \mathrm{Pd}, \mathrm{Pt}$ and other materials in various combinations with Ag and Al.

As an initial screening procedure, candidate metal stacks were deposited on $\mathrm{p}-\mathrm{GaN} / \mathrm{SiC}$ and a variation of a reflectivity measurement was performed. This yielded a relative value for different metals deposited directly on p-GaN, which should be a better indicator of actual LED behavior than standard reflectivity measurements using metal coatings on glass slides. Figure 12 shows the relative reflectivity performance of a subset of metal/p-GaN/SiC stacks that were investigated. As shown, for

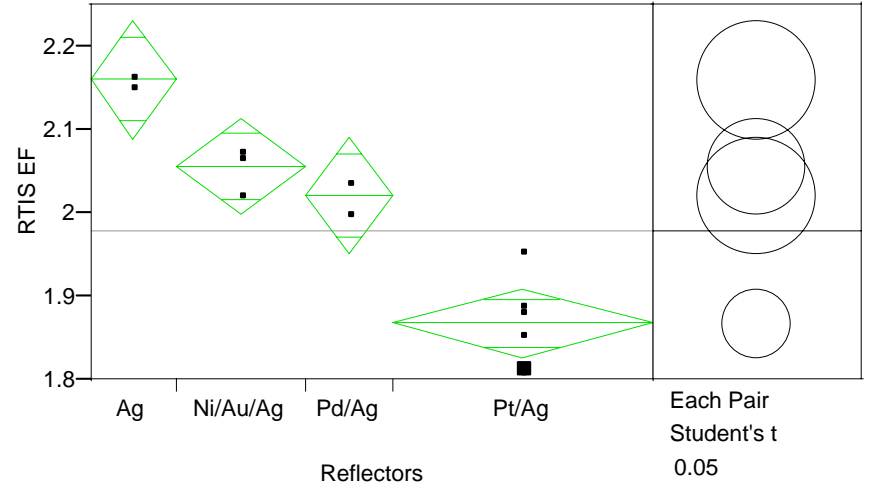

Figure 12 
this particular study Ag was found to be best, followed by NiAuAg, PdAg, and PtAg.

During Year 2 and Year 3 of the project, a great deal of effort was directed to finding a combination of contacts and process conditions that met the three key requirements for the mirror contact: (1) high reflectivity; (2) low contact resistance to p-GaN; and (3) reliable adhesion. GaN/SiC LEDs were fabricated with the more promising candidate contact schemes and compared to LEDs fabricated with a reference metal stack. Contact resistance measurements were also made using the transmission line technique. In brief, as a result of this work, new high reflectivity contacts were found that boosted the LED brightness by as much as 15\%. Additional contact schemes were found that boosted the brightness by as much as $22 \%$ but these were deemed unsuitable in practice because of either high voltage or adhesion problems.

\section{Voltage Improvement}

Another area that was addressed in Year 2 was a relatively high operating voltage of $\sim 3.9 \mathrm{~V}$ for the vertical geometry XB900 chip, compared to a fundamental voltage of $\sim 2.7 \mathrm{~V}$ for a blue LED. The high voltage was determined to be partly due to parasitic resistance caused by the $\mathrm{SiC}$ substrate. Researchers at Cree in North Carolina worked on the problem independently of the NETL project and made improvements to the baseline $\mathrm{SiC}$ material. Under the NETL project, power LED chips were fabricated using the improved material. In

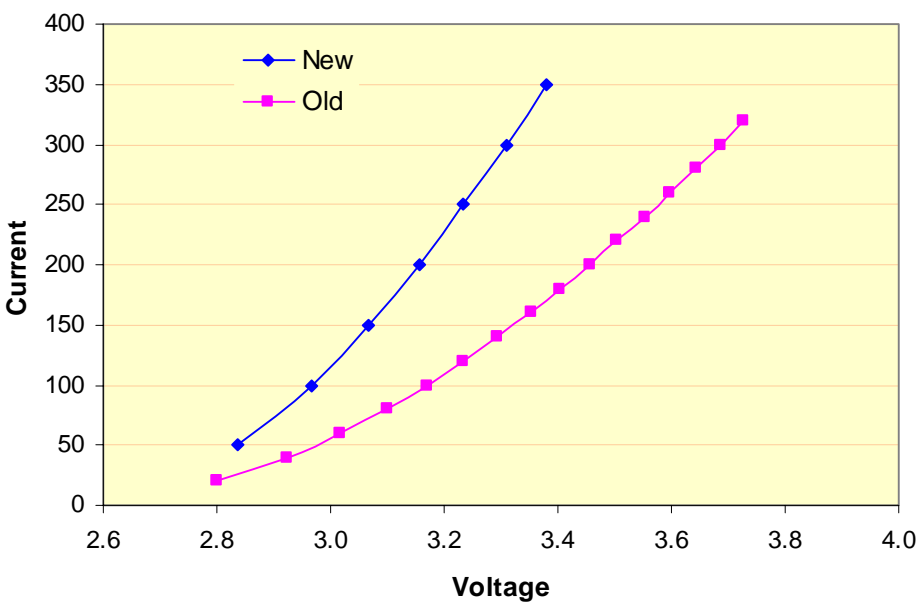

Figure 13 addition, the trade-off between low operating voltage and high brightness was re-evaluated for the new material, which resulted in a minor modification to the chip design. Figure 13 shows typical current-voltage curves for LEDs based on the old and new material. The diode operating voltage at $350 \mathrm{~mA}$ was reduced to $\sim 3.4 \mathrm{~V}$ typical, and as low as $3.1 \mathrm{~V}$ was observed in some devices.

\section{Blue LED Efficiency Summary}

For convenience, in this section the overall improvement over time of 1-watt class LEDs is summarized since the individual improvements described in the previous sections generally were not additive. Also, they did not take into account improvements in nitride material achieved by Cree's internal research and development programs.

Table 3 shows the status of blue $(460-470$ $\mathrm{nm})$ power LED performance as a combined result of the chip design iteration process and improved materials over the course of the NETL project. Overall, the chip performance approximately doubled in terms of the wall plug efficiency. Of this improvement, approximately half was due to the work performed directly under the NETL project. At the end of Year 3, blue LEDs with external quantum efficiency of $32.5 \%$, and wall plug

\begin{tabular}{|l|c|c|c|}
\hline Date & Flux (mW) & EQE (\%) & WPE (\%) \\
\hline Y1 June ‘02 & 180 & 19.5 & 13.2 \\
\hline Y2 January ‘03 & 230 & 25 & 20 \\
\hline Y2 July ‘03 & 270 & 29 & 22 \\
\hline Y3 July ‘04 & 310 & 32.5 & 26.5 \\
\hline
\end{tabular}

Table 3. Performance status of blue power LEDs showing the improvement by project year. Values are for a chip on a TO-39 header with epoxy encapsulation, operating at $350 \mathrm{~mA}$. 
efficiency of $26.5 \%$ at $350 \mathrm{~mA}$ were achieved, which, to the best of our knowledge, were world records for comparable devices at the time. As is generally the case, the wall plug efficiency of the blue LEDs was lower than the external quantum efficiency due to the series resistance of the device. For reference, LEDs based on more mature technologies (GaP, AlGaAs) have achieved efficiency levels of up to $60 \%$ so, despite the solid progress made on this project, there remains considerable room for further improvement.

As noted above, work during Year 1 was also directed to UV (400 nm) LEDs, which demonstrated some interesting advantages over blue LEDs at high current. Only a small amount of effort was directed towards this wavelength range in Year 2 and 3 due to the absence of available phosphors for converting the short wavelength light to usable white light. However, we note that the chip improvements described here are expected to work similarly for UV LEDs since the wavelength differs by only $\sim 15 \%$ and the reflectivity of most metals of interest is nearly constant in this range.

\section{White LEDs}

Throughout the project, white power LEDs were fabricated by combining blue power LED chips that incorporated the latest features for efficient light extraction that were developed under the NETL project. Chips were mounted on a reflectively coated TO-39 header, then coated with the phosphor and encapsulated in a clear epoxy resin with a refractive index of $\sim$ 1.5. The phosphor volume and concentration were controlled to yield a white light whose color point lay close to the black body curve, with a correlated color temperature of $\sim 6000 \mathrm{~K}$ (often referred to as a “cool” white). A representative spectrum for a white LED thus formed is shown in

Figure 14.

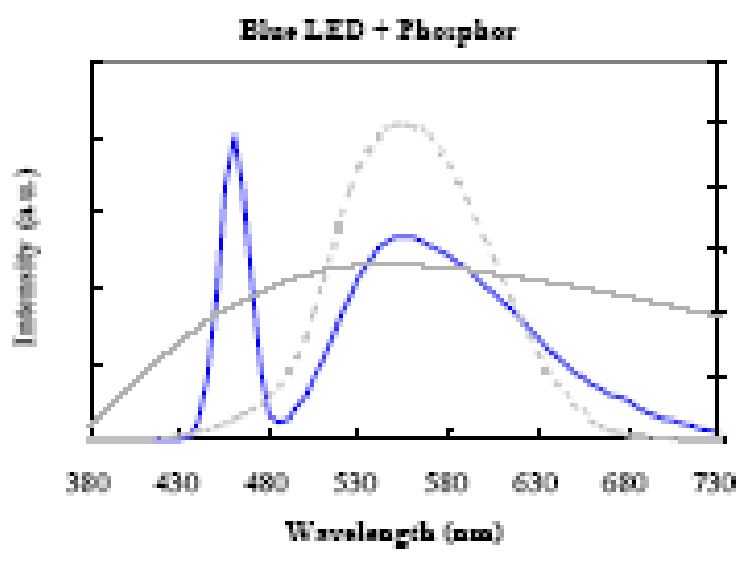

Figure 14

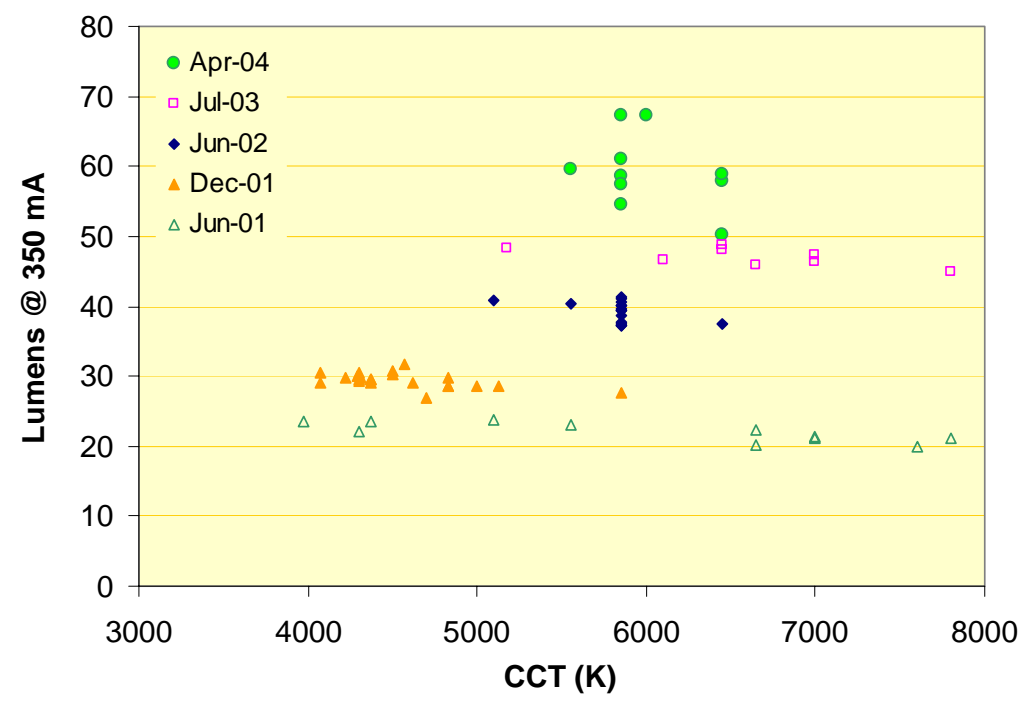

As shown in Figure 15, the total luminous output of the white lamps increased over time along with the performance of the blue power LEDs. Up to 67 lumens at $350 \mathrm{~mA}$ was demonstrated using the latest generation of blue LEDs. To our knowledge, at the time this was a record for a single chip operating in the 1-watt input class. It also represented a three-fold increase in luminous output from the start of the project.

Figure 15: Historical luminous output of white lamps fabricated on the project using single 1-watt class blue LED chips as the primary emission source. 
Figure 16 shows the luminous output and luminous efficacy of one of the high performance white LEDs as a function of drive current. The luminous efficacy of the lamp exceeded 60 lumens per watt up to a drive current of $300 \mathrm{~mA}$, with a total output of 60 lumens. The peak efficacy was over 70 lumens per watt at low currents $\left(\begin{array}{ll}\sim 0 & \mathrm{~mA}\end{array}\right)$ where the blue emitter wall plug efficiency peaks. From these results it was estimated that 16-20 similar LEDs would be required to meet the end-ofproject deliverable of a 1000

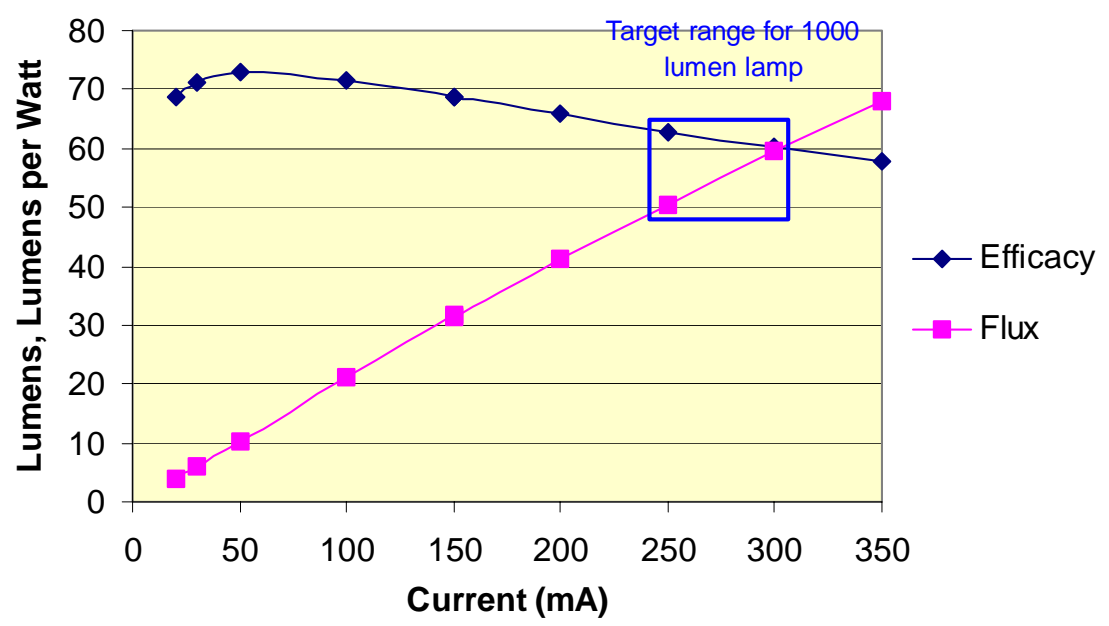

Figure 16: Luminous output and efficacy of white (CCT $~ 6000 \mathrm{~K})$ LED lamp as a function of drive current. The lamp used the latest blue chip technology developed on the project.

lumens lamp operating at 60 lumens per watt. Based on this input and other system design constraints learned over the course of the project, components (optics, circuit boards, drivers) for the 1000 lumens lamp were designed and ordered from outside vendors. Additional details are provided in the section on Task 3 later in this report.

It is also worth noting that the LEDs were capable of operating at significantly higher drive current than $350 \mathrm{~mA}$. At a drive current of $1 \mathrm{~A}$, the high performance white LED emitted over 140 lumens of white light with an efficacy of 35 lumens per watt. The reduced efficacy resulted from the internal quantum efficiency roll-off and increased operating voltage of the primary blue emitter at high currents.

On related topic, a press release in September 2003 announced Cree's demonstration of a white LED lamp with an efficacy of up to 74 lumens per watt (see Appendix B). This was achieved using a 0.3 x $0.3 \mathrm{~mm}^{2}$ chip, some of whose design features were developed on this project, operating at $20 \mathrm{~mA}$. At the time this result established a new performance benchmark for white LEDs.

\section{Monochrome LED Arrays}

An important deliverable for Task 1 was to scale up the total optical output from the blue (or UV) emitters by an order of magnitude or more by combining multiple devices in a compact array. Targets were to demonstrate $4 \mathrm{~W}, 8 \mathrm{~W}$ and $12 \mathrm{~W}$ output after Year 1, 2, and 3, respectively. Later in the project we were able to draw on the packaging technology developed under Tasks 2 and 3 for this purpose. Based on the improved performance level of the individual LEDs after the project's first year it was estimated that the $4 \mathrm{~W}$ target would require a module operating at a total of $\sim 25 \mathrm{~W}$ input. Initially, however, a temporary solution was provided using an array of TO-39 header lamps and a fan-cooled heat sink, as shown in Figure 17. The alternative to the fan-cooled heat sink would have been to operate the array in a pulsed current mode.

Three LED array modules were fabricated, one each of UV, blue, and white (blue LED + yellow phosphor). Each array consisted of eight LEDs mounted on TO-39 headers, which were attached to a 2" x 2" CPU heat sink. Figure 18 shows a picture of a module. The heat sink included a built-in, $12 \mathrm{~V}$ fan for active cooling during high power testing. Thermal characterization of this type of module with all 8 LEDs operating indicated an average junction-to-ambient thermal resistance $\left(\theta_{j a}\right)$ 
of $\sim 3{ }^{\circ} \mathrm{C} / \mathrm{W}$. To measure the optical properties as a function of drive current, each module was placed inside an integrating sphere and operated using an external power supply.

Figure 19 shows the measured flux of the blue and UV modules as a function of input power. Again, the graph shows the dramatically superior performance of the UV module compared to the blue module, which unfortunately could not be fully utilized due to the absence of suitable phosphors as previously discussed. At $22.5 \mathrm{~W}$ input, which corresponded to $600 \mathrm{~mA}$ per LED, the output of the UV array reached $4.2 \mathrm{~W}$, thereby meeting the Year 1 milestone. The flux increased to $4.7 \mathrm{~W}$ at $28.5 \mathrm{~W}$ input (700 mA per LED). The output power of the blue module peaked at $1.7 \mathrm{~W}$ at 24 $\mathrm{W}$ input before decreasing as it was driven harder, which was attributed it to self-heating effects.

In Years 2 and 3, the target performance was met using blue LEDs combined with the high power modules described in later sections of this report. A total of 36 chips, and 16 chips operating at up to $2 \mathrm{~W}$ input per chip were used to achieve the $8 \mathrm{~W}$ and $12 \mathrm{~W}$ output targets, respectively. Fewer chips were needed in the third year due to the improvement in device performance. In hindsight, the specified output requirements of the monochrome LED arrays were excessive relative to the white lamp targets of Task 3 and such high levels of light output were achievable from a compact form factor only when using an actively cooled heat sink due to the large amount of heat to be

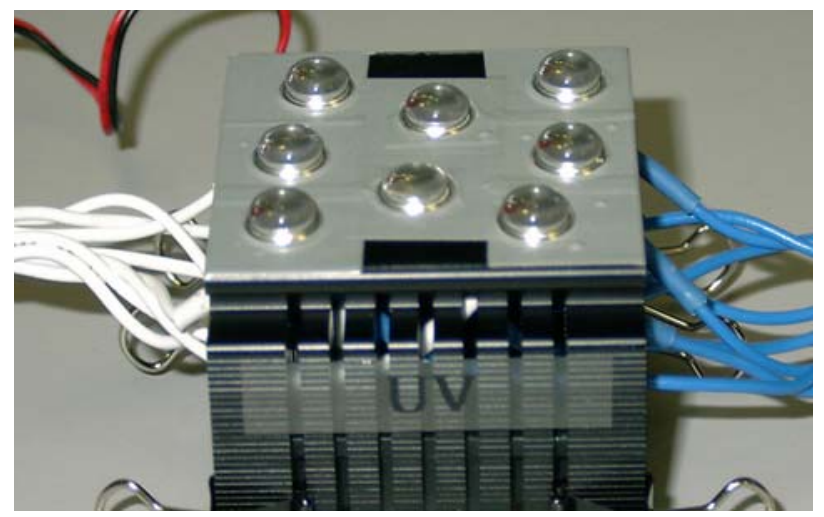

Figure 18

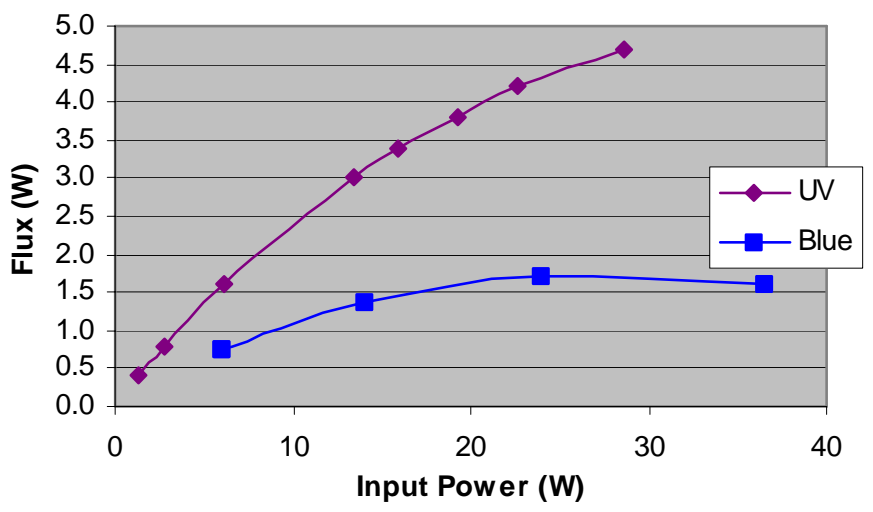

Figure 19 dissipated. 


\section{TASK 2: THERMAL PACKAGE}

\section{Background}

LEDs with wall plug efficiency of 30\%, approximately the goal under this project, convert the remaining $70 \%$ of electrical power to heat. The power levels being targeted (10-30 W input) therefore require the efficient dissipation of substantial amounts of heat from the LED chip array. Figure $\mathbf{2 0}$ is a schematic of the heat flow in a prototypical LED power package. Very little heat flows directly from the chip to ambient because of its small size and low operating temperature $\left(<100{ }^{\circ} \mathrm{C}\right)$. Instead, the predominant heat flow path is from the chip to an attached heat sink via various interfaces, then to ambient. The project's second main task involved the development of high power packages able to handle up to $30 \mathrm{~W}$ input while maintaining the LED chip junction temperature below $100{ }^{\circ} \mathrm{C}$. Assuming room temperature ambient conditions, this target translated to a package with an overall junction-to-ambient thermal resistance of $\sim 3{ }^{\circ} \mathrm{C} / \mathrm{W}$.

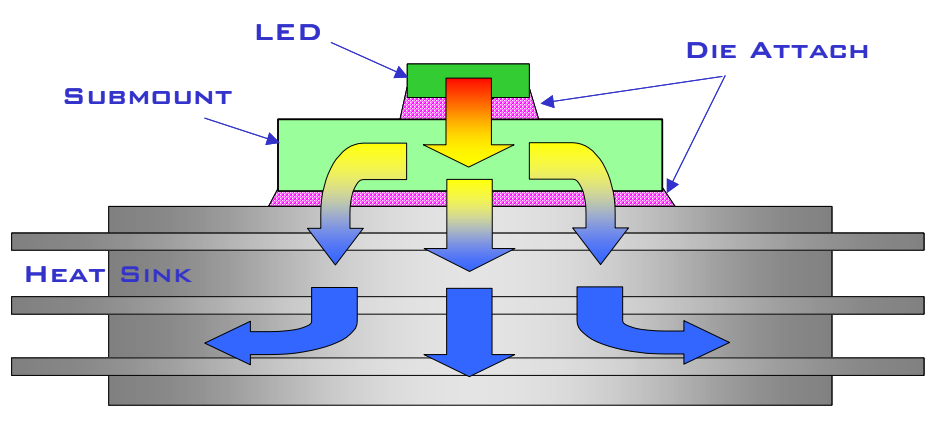

Figure 20

\section{Baseline Thermal Characterization Results}

To establish a baseline, we first evaluated the thermal resistance of single InGaN power LEDa mounted on various commercial power packages using Ag-filled epoxy. The packages under evaluation were commercially available designs made of CuW that are typically used for high-power semiconductor devices but are not optimized for optical devices. For comparison, we also evaluated the thermal performance of the TO-39 headers used as the reference optical package for our LEDs.

The basic thermal characterization technique was to measure the junction (i.e. device) temperature as a function of input power. This was achieved by first obtaining a calibrated curve of the operating voltage of the LED at low current versus temperature using a programmable oven and a multimeter. Then the LED was operated under the steady-state high power conditions of interest except for occasional brief measurements at the low current voltage previously calibrated. The device under test therefore acted as its own thermocouple.

An overview of the results is presented in Table 4. As expected, the junction-to-ambient thermal resistance $\left(\theta_{j a}\right)$ decreased with increasing package size due to the larger surface area for dissipating heat to ambient. For a chip carrier by itself, the best number measured was 59 ${ }^{\circ} \mathrm{C} / \mathrm{W}$ for a package that measured $7 \times 20 \mathrm{~mm}^{2}$. Such performance would be sufficient to allow continuous $\sim 1.4 \mathrm{~W}$ operation of a device while maintaining a junction temperature below $100{ }^{\circ} \mathrm{C}$. By comparison, the LED on a TO-39 header exhibited an exceedingly high $\theta_{j a}$ of $\sim 200{ }^{\circ} \mathrm{C} / \mathrm{W}$ due to the poor thermal conductivity of the materials used in the header construction.

\begin{tabular}{|l|c|c|}
\hline \multirow{2}{*}{ Package Type } & \multicolumn{2}{|c|}{$\begin{array}{c}\text { Ave. Thermal } \\
\text { Resistance ( }\end{array}$} \\
\cline { 2 - 3 } & $\begin{array}{c}\text { Package } \\
\text { only }\end{array}$ & $\begin{array}{c}\text { On 1"x1" } \\
\text { heat sink }\end{array}$ \\
\hline TO-39 & 196 & 57 \\
\hline $\begin{array}{l}\text { Small power } \\
\text { package }\end{array}$ & 86 & 50 \\
\hline $\begin{array}{l}\text { Medium power } \\
\text { package }\end{array}$ & 72 & 45 \\
\hline $\begin{array}{l}\text { Large power } \\
\text { package \#1 }\end{array}$ & 62 & 40 \\
\hline $\begin{array}{l}\text { Large power } \\
\text { package \#2 }\end{array}$ & 59 & 38 \\
\hline
\end{tabular}

Table 4: Junction-to-ambient thermal resistance for XB900 LED chip on various semiconductor packages 
As shown in Table 4, $\theta_{j a}$ was significantly improved by attaching the package to a larger heat sink. Placing the package in intimate contact with a 1 " $\mathrm{x} 1$ ” aluminum heat sink reduced the thermal resistance of the LED on a $7 \times 20 \mathrm{~mm}^{2}$ package to $38{ }^{\circ} \mathrm{C} / \mathrm{W}$, and that of the LED on a TO-39 header to $57^{\circ} \mathrm{C} / \mathrm{W}$. Increasing the size of the heat sink (or rather reducing its thermal resistance to ambient) improved $\theta_{j a}$ even further.

\section{Advanced Die Attach Materials}

Another area that was shown to be critical to the thermal performance was the die attach material used to attach the LED chip to the package. To investigate this, we compared the thermal resistance of LED chips mounted in the conventional manner with Ag epoxy, and LED chips that were first solder-bonded to an intermediate heat spreader. The

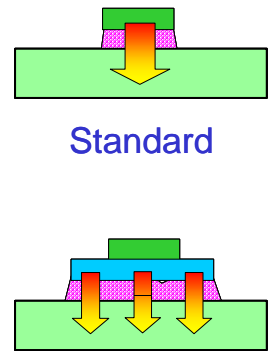

Die bonded to Heat Spreader

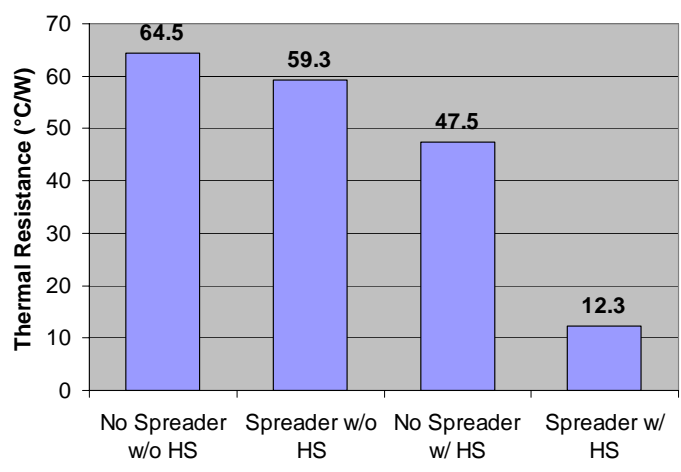

Figure 21

two configurations are drawn schematically in Figure 21 along with the measured $\theta_{j a}$. Interestingly, very little difference was observed when the submount itself was the primary heat dissipation surface. However, once the package was attached to a larger heat sink, $\theta_{j a}$ for the solder bonded decreased to $\sim 12{ }^{\circ} \mathrm{C} / \mathrm{W}$, confirming that the conventional die attach was a thermal bottleneck.

As part of the collaborative effort on this project, researchers at LBNL evaluated novel die attach materials. Sn-3Ag alloy ( $97 \mathrm{wt} \% \mathrm{Sn}, 3 \mathrm{wt} \% \mathrm{Ag}$ ) was selected as one possible candidate to bond the $\mathrm{SiC}$ wafer to a variety of substrates. The liquidus temperature of the alloy is $\sim 221^{\circ} \mathrm{C}$ and it can be used to prepare joints at $\sim 240-250^{\circ} \mathrm{C}$. The spreading behavior of Ag-3Sn on a variety of materials in different atmospheres was studied in order to evaluate the possibility of using it as a brazing alloy for the LED system.

Figure 22 shows the spreading of Ag-3Sn on a polished $\mathrm{Fe}-42 \% \mathrm{Ni}$ substrate at $250^{\circ} \mathrm{C}$. The data were taken using a drop set-up transfer inside an induction furnace with a tungsten heating element and high-speed video. A small piece of Ag-3Sn solder ( 0.1-0.2 g) was placed on an alumina substrate inside a furnace.

After taking care to remove surface oxides, reflow the solder, and stabilize the temperature at $250^{\circ} \mathrm{C}$, the $\mathrm{Fe}-42 \% \mathrm{Ni}$ substrate was lowered until it touched the solder surface and the liquid spread on it, transferring from the $\mathrm{Al}_{2} \mathrm{O}_{3}$ plate to the alloy. Spreading was recorded using a high-speed motion analysis system with a digital camera able to take up to 500 frames per second. Contact angles lower than $90^{\circ}$ are reached after less than a second, which indicates that Sn-3Ag would be a good candidate to bond Fe alloys.

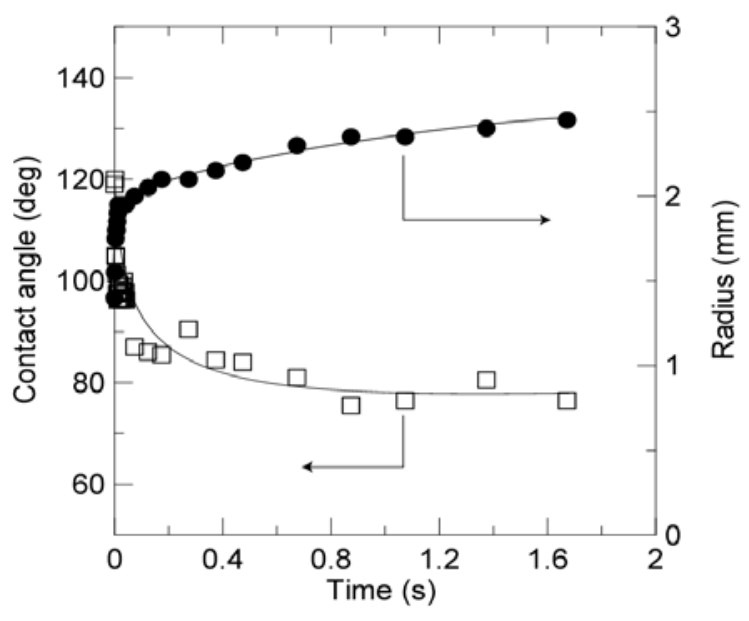

Figure 22. Variation of the contact angle and drop radius with time during the spreading of a small drop of Sn-3Ag on $\mathrm{Fe}-42 \% \mathrm{Ni}$ at $250^{\circ} \mathrm{C}$ in $\mathrm{Ar}+5 \% \mathrm{H} 2$. 


\section{Compact LED Module Designs}

Since the TO-39 header, a picture of which is shown in Figure 23(a), was clearly unsuitable for the project's LED array goals due to its poor thermal characteristics and relatively large footprint, several novel LED module prototypes were designed and demonstrated over the course of the project. When designing a suitable format for a compact LED array both thermal and optical considerations have to be taken into account. In Year 1, the primary focus was on the module's thermal properties, which led to the GEN I and GEN II LED modules shown in Figures 23(b) and 23(c), respectively. In Year 2, a GEN III module was developed around a four-chip layout for a more compact source (see Figure 23(d)) that incorporated high reflectivity coatings on all exposed surfaces to reduce light losses. In all cases, the modules were designed for mounting to a separate heat sink.

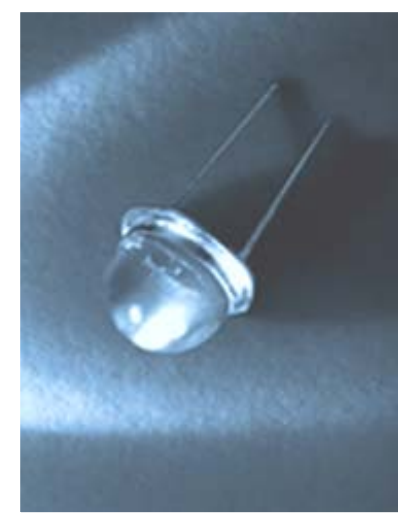

Figure $23(a)$

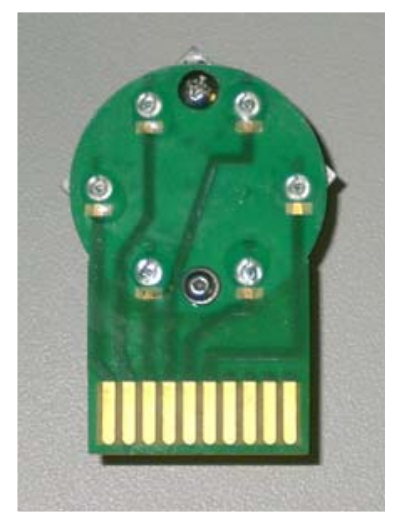

(b)

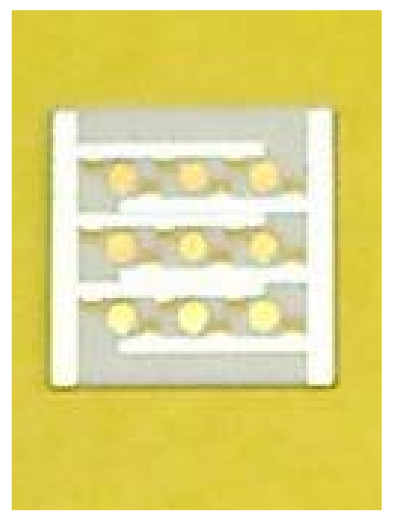

(c)

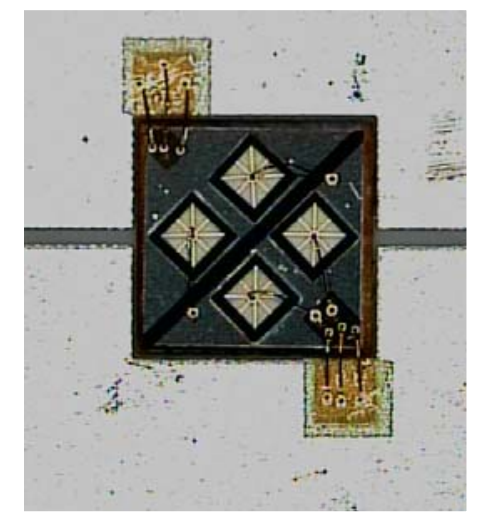

(d)

In the GEN I module LED chips were mounted directly to a large area metal-backed printed circuit board. The design was scaleable in the sense that any number of die per package could be incorporated in principle, although our designs were for 2-chip and 6-chip variations. The GEN II module was similar in concept but included high performance materials and the addition of a heatspreading submount under each LED chip. However, the optical performance of both those modules was relatively poor due to multiple non-reflective surfaces. The GEN III module used basically similar technology as the GEN II module from the point of view of heat dissipation, with improved optical characteristics.

\begin{tabular}{|c|c|c|c|}
\hline $\begin{array}{c}\text { Package I } \\
\text { Module } \\
\text { Design }\end{array}$ & \multicolumn{2}{|c|}{ Relative Optical Efficiency } & $\begin{array}{c}\text { Single Chip } \\
\text { Thermal } \\
\text { Resistance } \\
\text { ('C/watt) }\end{array}$ \\
\cline { 2 - 3 } & Blue LED & White LED & 55 \\
\hline TO-39 & 100 & 100 & 17.7 \\
\hline GEN I & 40 & 40 & 12.3 \\
\hline GEN II & $>90$ & 60 & $\mathrm{n} / \mathrm{a}$ \\
\hline GEN III & $>90$ & $>90$ & \\
\hline
\end{tabular}

The evolution in optical and thermal characteristics of the different module designs over the course of the project is summarized in Table 5. With the final GEN III module we were able to achieve a design whose optical efficiency was at least $90 \%$ (and probably closer to $100 \%$ ) that of the TO-39 header for both blue and white lamps. We were also able to reduce

Table 5. Key performance metrics of different generation high power LED modules developed on the project. Optical performance, on a per chip basis, is measured relative to a chip mounted on a reflective TO-39 header with epoxy encapsulation $(=100)$. For thermal measurements, modules were mounted on 2-inch square Al heat sinks. the module's thermal resistance (including the heat sink) to $12{ }^{\circ} \mathrm{C} / \mathrm{W}$ for single 0.9 x $0.9 \mathrm{~mm}^{2}$ chip operation. 


\section{Performance with Multiple Devices Operating}

It is not obvious from the results listed in Table $\mathbf{5}$ that the project goals for Task 2 were met but this was in fact the case. An interesting aspect of the heat dissipation problem from LEDs is that the heat flow is limited to a large degree by the footprint of the chip itself. As a result, the area of the chip/package interface is a very important factor in determining the thermal resistance. Since the total area is increased by using multiple chips so the overall thermal resistance of the LED module is reduced.

For example, while the thermal resistance of the GEN I module for a single chip operating was 55 ${ }^{\circ} \mathrm{C} / \mathrm{W}$, the thermal resistance of a six LED version measured an average of $8{ }^{\circ} \mathrm{C} / \mathrm{W}$, and as low as 7.1 ${ }^{\circ} \mathrm{C} / \mathrm{W}$. At room temperature it was therefore possible to operate the six LED module at $10 \mathrm{~W}$ total input - approximately $1.6 \mathrm{~W}$ per chip - while maintaining a junction temperature below $100{ }^{\circ} \mathrm{C}$, thereby meeting the Year 1 milestone.

Similarly, the thermal performance of the GEN III modules was characterized as a function of the number of LED chips, and with and without the module mounted to a heat sink. Those results are summarized in Table 6. Qualitatively, the results agreed with those from earlier generation modules, namely that the thermal resistance decreased with increasing number of chips on the module (although not on a per chip basis). For the module with four chips - like those used for the 1000 lumen lamp prototypes in Task 3 the thermal resistance was $5.5^{\circ} \mathrm{C} /$ watt. With the same technology except using nine LED chips to increase the active device area, the thermal resistance was further reduced to 1.7 ${ }^{\circ} \mathrm{C} /$ watt.

\begin{tabular}{|c|c|c|}
\hline \multicolumn{3}{|c|}{ Junction-to-Ambient Thermal Resistance $\left({ }^{\circ} \mathrm{C} /\right.$ watt) } \\
\hline Number of chips & Module only & On heat sink \\
\hline One & 59 & 12.3 \\
\hline Four & 52 & 5.5 \\
\hline Nine & 21 & 1.7 \\
\hline
\end{tabular}

Table 6. GEN III LED module thermal performance.

It was also instructive to look at the increase in the module's metal base temperature, which was done by placing a thermocouple directly on it. Figure $\mathbf{2 4}$ plots the measured junction temperature and base temperature as a function of input power for a GEN III module with four chips on a heat sink. The base-to-ambient thermal resistance was $2.6{ }^{\circ} \mathrm{C} /$ watt, which yielded a junction-to-base thermal resistance of only $2.9{ }^{\circ} \mathrm{C} /$ watt. This result highlighted two points. First, the submount wafer and die attach method employed resulted in very efficient heat flow from the LED chips to the base of the module. Second, since the junction-to-base thermal resistance is independent of whether or not a heat sink, is attached, the result again emphasized the importance of the heat sink in determining the overall efficiency of the heat dissipation process.

Another way of looking at the issue is shown in Figure 25. In this case, the temperature of the metal base of one of nine GEN III modules in a 1000 lumen lamp prototype was monitored as a function of the total power being supplied to the prototype. Two data curves are plotted showing the effect of active

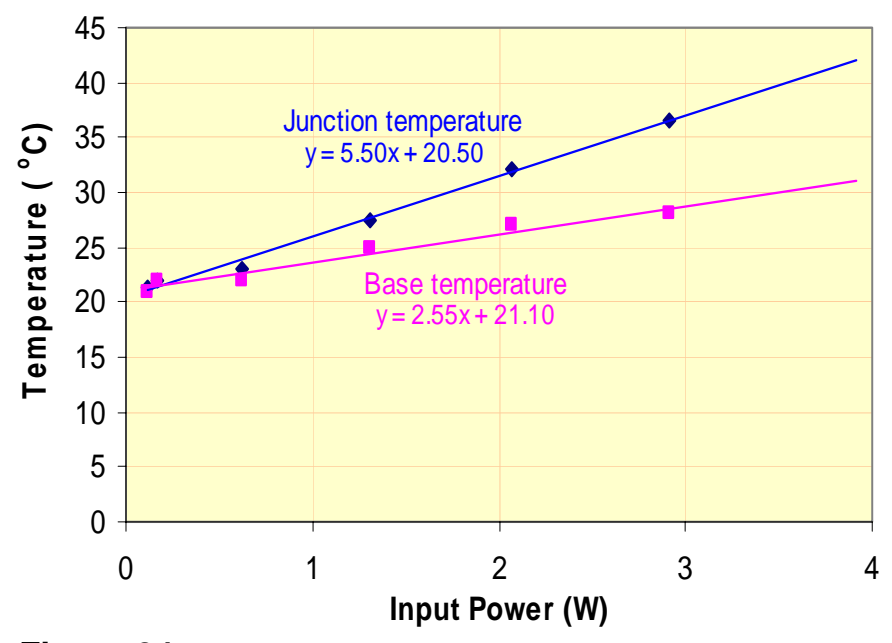

Figure 24 
cooling using a fan. With natural convection cooling (i.e. no fan), the module temperature was found to increase dramatically once the power to the prototype exceeded $\sim 15$ watts input. The sharp increase in base temperature at higher power indicated that the heat sink could handle only so much heat input before its own temperature started to rise significantly. In contrast, by having a fan provide active cooling of the heat sink, the base temperature rise was much more gradual up to 75 watts input. The implications for solid-state lighting are that the lamp housing plays an important role in providing adequate heat conduction

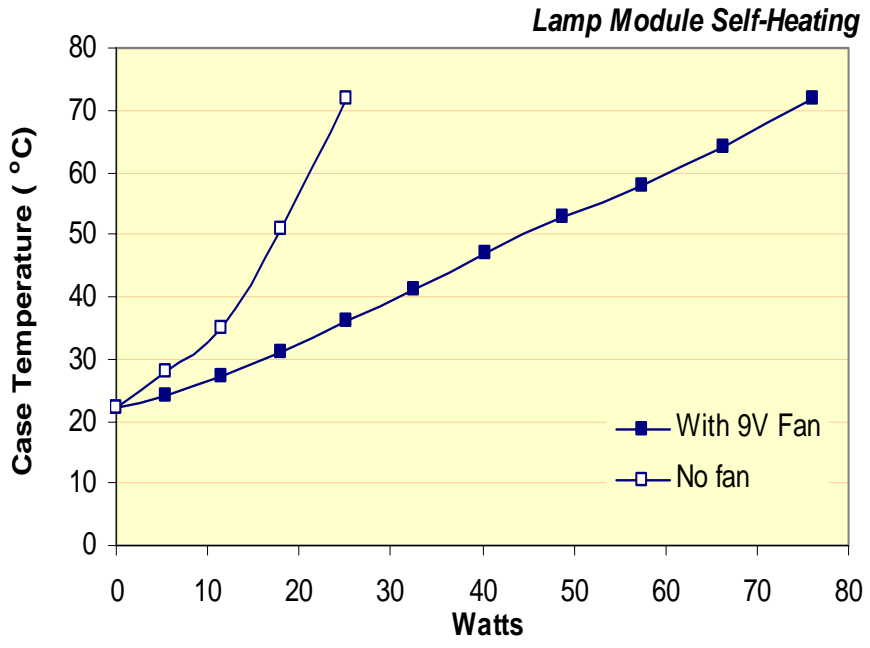

Figure 25 to ambient.

Assuming white LED efficacy of 50 lumens per watt, the data in Figures $\mathbf{2 4}$ and $\mathbf{2 5}$ showed that the developed technology was sufficient to meet the end-of-project goal of a passively cooled (no fan) 1000 lumen lamp. The lamp would operate at 20 watts input, corresponding to a base temperature of $\sim 55^{\circ} \mathrm{C}$. Then adding the $2.9^{\circ} \mathrm{C} /$ watt junction-to-base thermal resistance and each 4-chip module operating at $\sim 5$ watts, one arrives at a junction temperature of approximately $70^{\circ} \mathrm{C}$ above ambient for the system. This met the end-of-project milestone of maintaining a junction temperature of less than $100^{\circ} \mathrm{C}$ with room to spare.

\section{TASK 3: WHITE LED LAMP}

Listed as a separate task, the demonstration of the high flux lamps on the project largely involved the integration of the separate technology elements developed under Tasks 1 and 2. Multiple modules fabricated using high performance blue LED chips were combined in a compact package to achieve the total luminous output targeted under Task 3.

\section{300 Lumens Milestone}

The initial project target was to demonstrate a prototype white lamp with at least 300 lumens output by May 2003. Figure 26 shows the prototype, which consisted of three of the GEN III modules (four blue LED chips each, with phosphor-loaded encapsulation) mounted on a passively cooled heat sink (i.e. natural convection) for thermal management. The LED chips incorporated features developed for high efficiency under Task 1 through the middle of Year 3. The heat sink dimensions were two inches in diameter, and 1.5 inches tall.

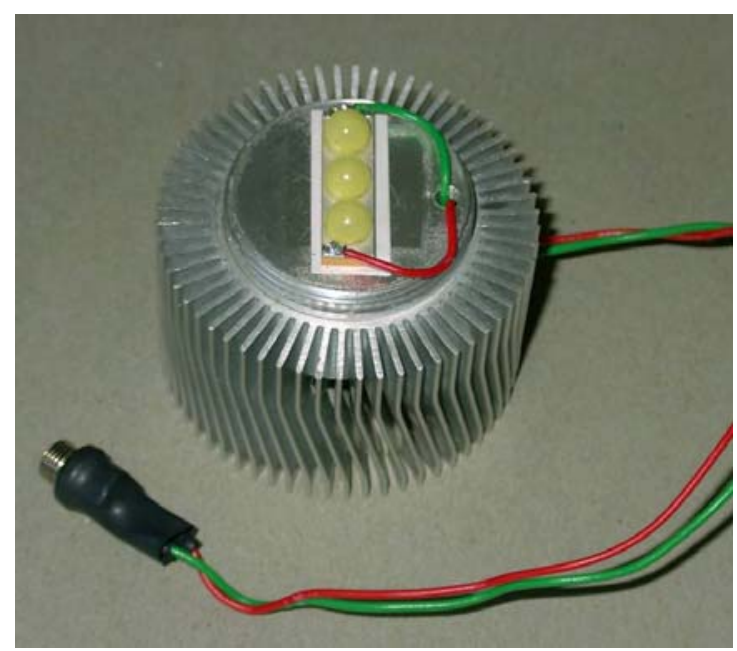

Figure 26 


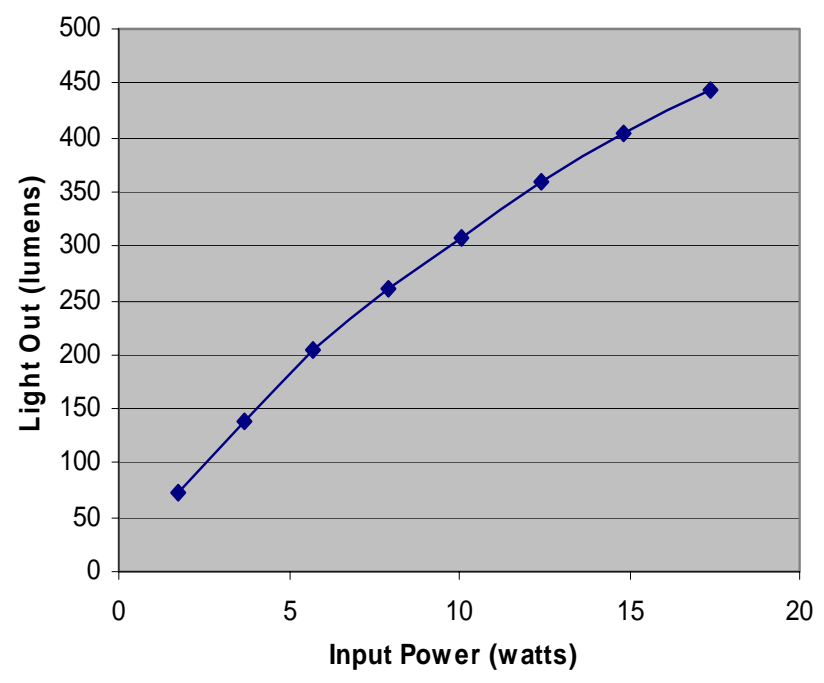

Figure 27 (a)

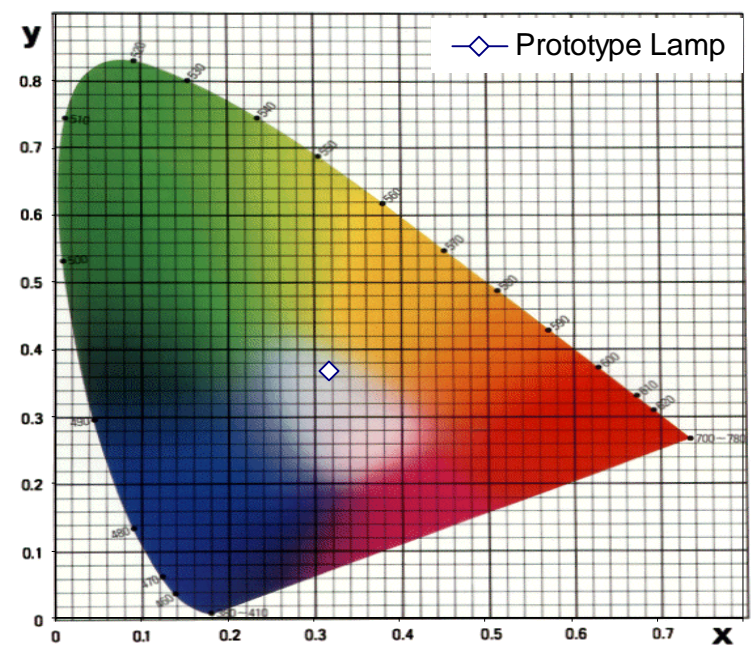

Figure 27 (b)

The lamp prototype was characterized using an integrating sphere and Figure 27(a) shows a plot of the measured output power in lumens as a function of electrical input power. Over 400 lumens was achieved at the designed operating point of $700 \mathrm{~mA}$ at 15 watts input ( $>27$ lumens/watt), exceeding the target milestone by 33\%. Figure $\mathbf{2 7}$ (b) shows the lamp angle averaged color point on a CIE diagram. The lamp's correlated color temperature was $5900 \mathrm{~K}$ and the color rendering index was $\sim 78$.

\section{1000 Lumens Milestone}

In order to demonstrate light output at the 1000 lumens level comparable to existing light sources additional GEN III modules were combined in a compact array. To put in perspective, 1000 lumens is roughly the same output as a conventional $60 \mathrm{~W}$ incandescent bulb. A picture of an LED lamp prototype in operation is shown in Figure 28(a). The number of modules (i.e. LED chips) was chosen to allow the 1000 lumens level of output to be reached with the LED chips operating close to their designed input of $\sim 350 \mathrm{~mA}$ per chip. As a result of the continuous improvement in device performance over the course of the project, the actual number of modules required therefore decreased over time.

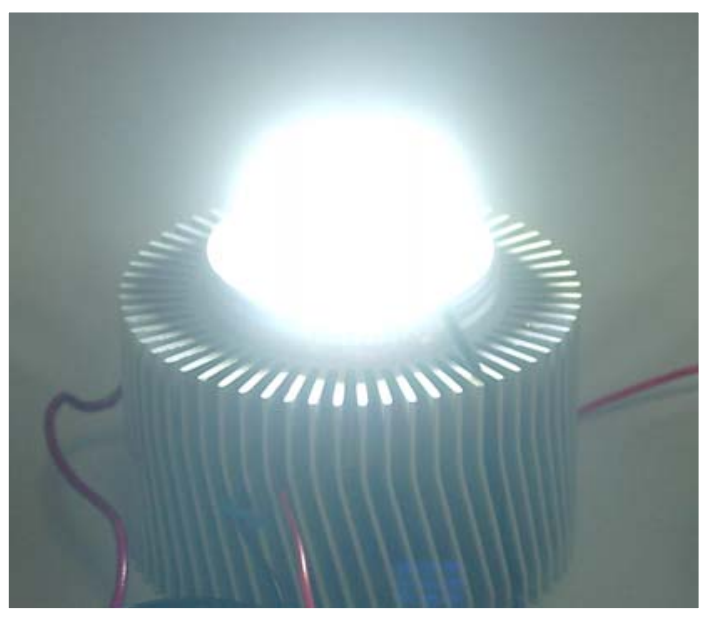

Figure 28(a)

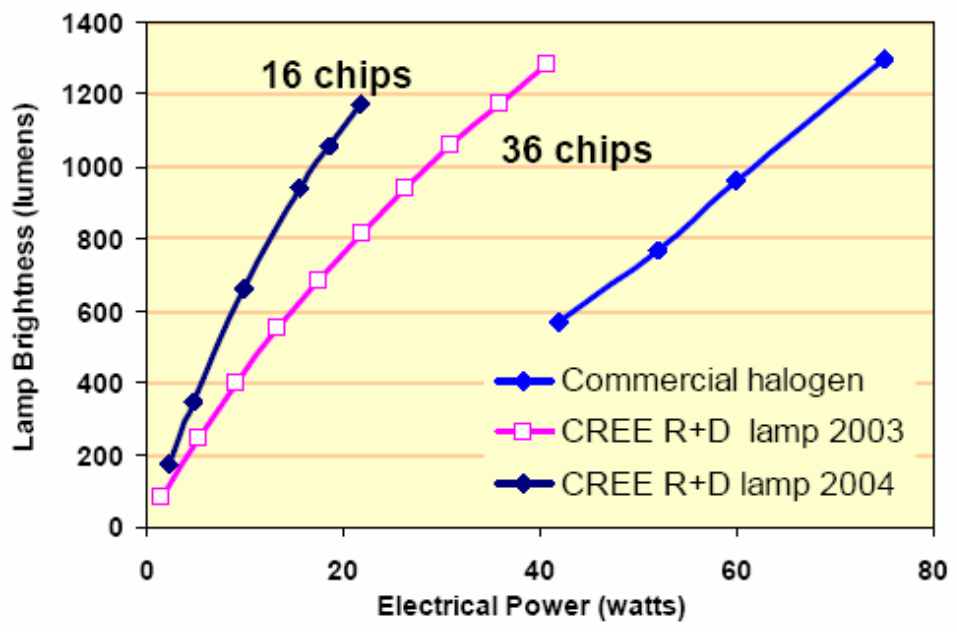

Figure 28(b) 
A 1000 lumen lamp was first demonstrated successfully at the beginning of Year 2. Several generations were subsequently built to incorporate improvements in chip brightness, thermal management, and phosphor integration techniques as these became available. Figure 28(b) shows the performance as a function of input power for two LED lamp prototypes fabricated in the middle of Year 2 and at the end of the project. The data were measured using an integrating sphere with the lamp operating in continuous mode. At the conclusion of the project the LED lamp output exceeded 1000 lumens at an efficacy of 55 lumens/W. Representative data for a commercial halogen lamp are also plotted for comparison. Despite just missing the target of 60 lumens/W, by the end of the project the LED lamp was more than three times as energy efficient as the conventional light source (although we should note that this comparison did not take into account the efficiency of the driver that would be required to operate an LED lamp off the electrical grid).

\section{MR16 Replacement LED Lamp}

For this subtask, the goal was to demonstrate a prototype LED lamp that could potentially be used as a replacement source for MR16 halogen lamps in terms of total output, footprint, and radiation pattern. To achieve this, LED optics were designed as an add-on reflector/lens component to be used in conjunction with Cree's XLamp ${ }^{\mathrm{TM}}$ power packages, samples of which became available for evaluation purposes during the project's Year 3. The intention was then to combine multiple LEDs on a printed circuit board to meet the total lumens output requirement (500 - 1000 lumens). It was decided to adopt this approach rather than to design and procure an entirely new package in order to leverage limited NETL funds off Cree's internal package development resources as much as possible.

\section{Optics Design}

Using ray-trace modeling software and some preliminary experimental data provided by Cree, our collaborators at Lawrence Berkeley National Laboratory designed optics to mimic the radiation pattern of a commercial MR16 halogen lamp. Compared to conventional white LED lamps, which are essentially a Lambertian source, the MR16 incorporates a reflector that directs light towards the forward viewing axis. A schematic of the lamp optics is shown in Figure 29(a). The overall part dimensions were approximately $6 \mathrm{~mm} \times 6 \mathrm{~mm} \times 5 \mathrm{~mm}$. Based on the LBNL design, the optics components were purchased from external vendors.
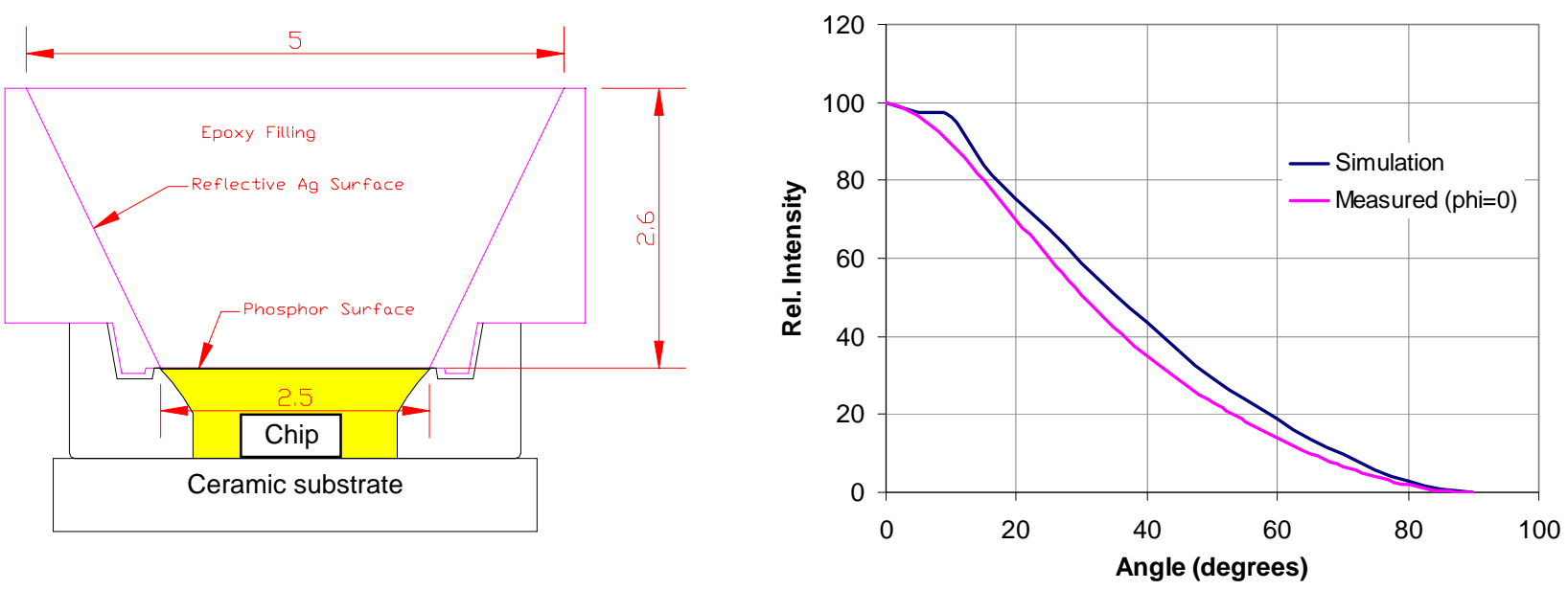

Figure 29: (a) Schematic of prototype optics for MR-16 replacement solid-state lamp component; (b) Comparison between simulated and measured far field intensity pattern. 
Figure 29(b) compares the measured far field intensity pattern of a typical lamp using the custom optics to the ray-trace simulation results. There was remarkably good agreement between the calculated beam pattern and the actual lamp output. Importantly, the on axis intensity of the lamp was significantly higher than a conventional Lambertian emitter due to the narrower viewing angle ( 30 degrees compared to 60 degrees half angle) provided by the custom optics.

\section{LED Lamp Prototype}

The MR16-type replacement lamp featured eighteen separate LED modules mounted on a printed circuit board attached to a heat sink. Each module combined a state-of-the art blue LED power chip with commercial yellow phosphor and the custom optics described above. Figure $\mathbf{3 0}$ shows the completed MR16-like LED lamp. At the designed operating point of $350 \mathrm{~mA}$ per LED, the total output of the lamp was in the range of 760-870 lumens, with an efficacy of 40 lumens per watt. The uncertainty in the value came about from measuring the lamp output in different orientations, and was probably a consequence of the lamp dimensions approaching the size limitations of our integrating sphere.

It is worth noting that the efficacy of the MR-16 lamps was significantly lower than the 1000 lumens lamp prototypes described earlier. The discrepancy is believed to be due in part to the additional optics. It highlights a tradeoff generally encountered with any light source between overall efficiency and control over the light directionality.

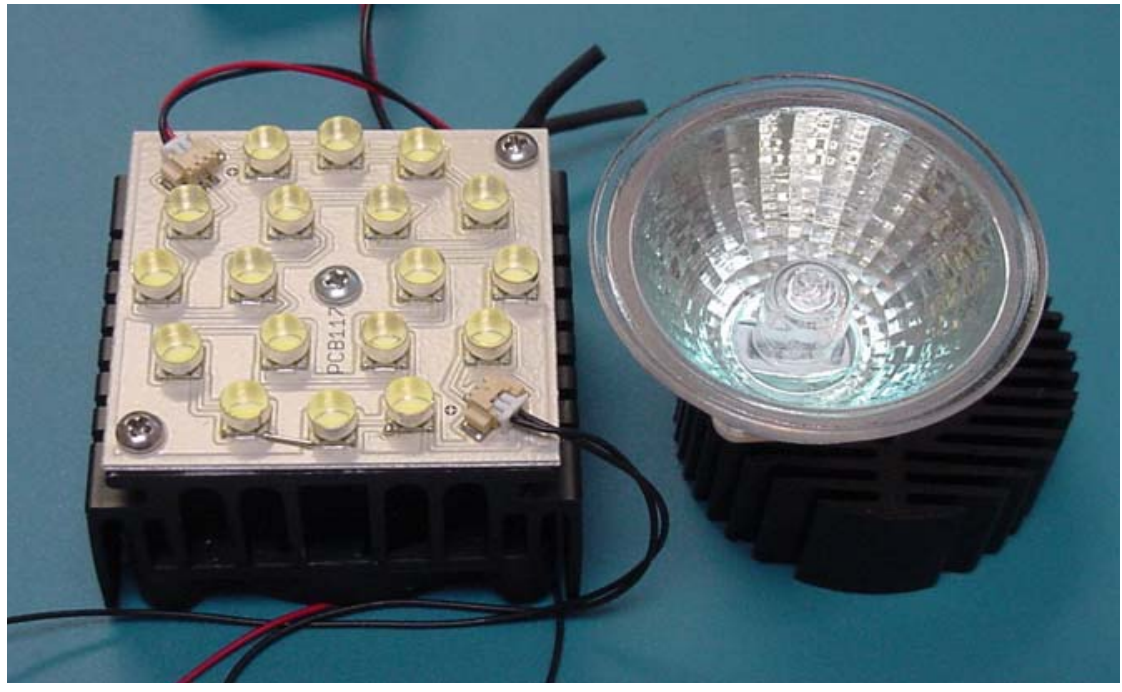

Figure 30. Compact solidstate lamp prototype and conventional MR16. The array of LED modules on the circuit board lies within a $50 \mathrm{~mm}$ diameter so the lamps' optical sizes are equivalent. Total output of the LED lamp was -800 lumens. The LED lamp's full width half maximum viewing angle is $\sim 60$ degrees.
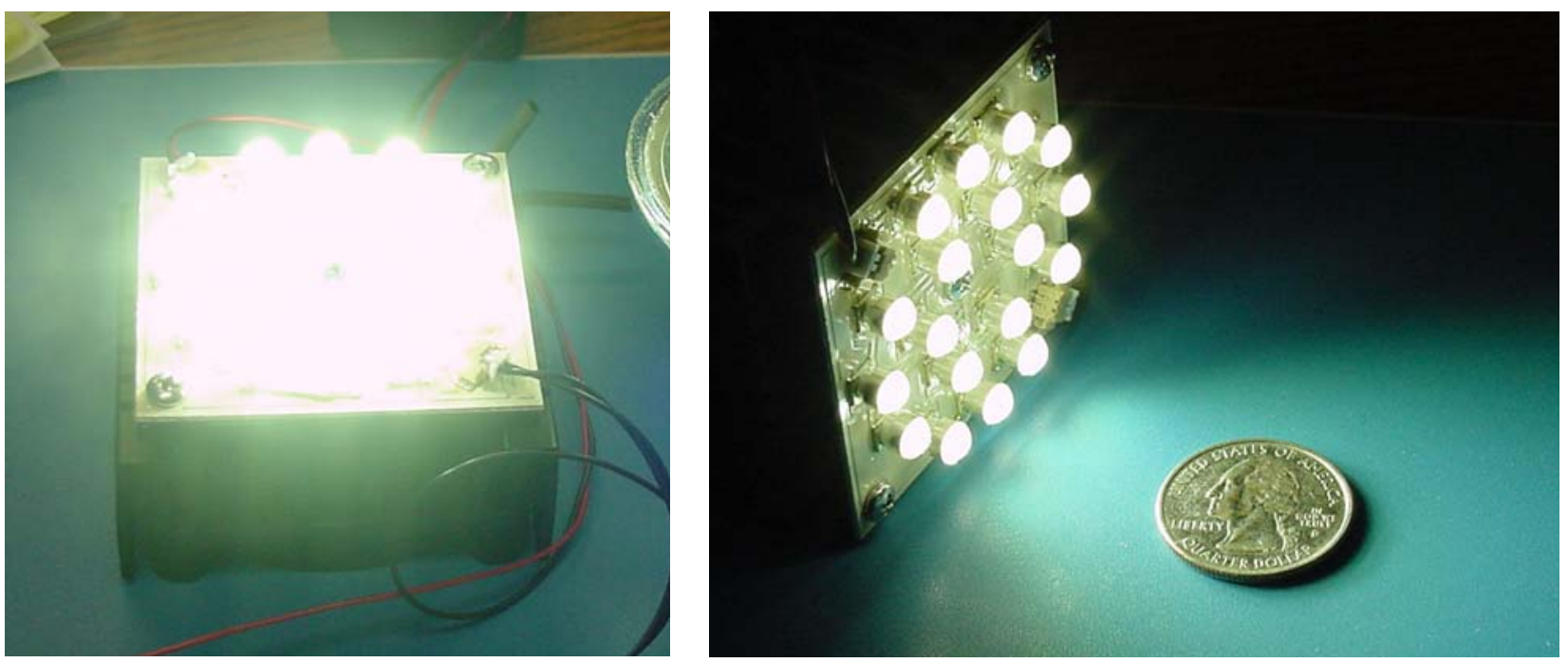


\section{TASK 4: LONG-LIFE 3-WATT LED MODULE}

\section{High Power White LED Life-Time}

Demonstrating high power LED modules with lifetime in excess of 5000 hours was added as a technical goal as a result of the project review at the end of Year 2.

White LED lamps were fabricated using the high power blue LED chips developed over the course of this project together with a commercial yellow phosphor and Cree's 7090 XLamp ${ }^{\mathrm{TM}}$ package, samples of which became available for evaluation purposes during Year 3. The XLamp incorporates various design features thought to be necessary for long life, including the use of high thermal conductivity materials and transparent encapsulation materials that are resistant to discoloration under the high optical flux density in the vicinity of the chip.

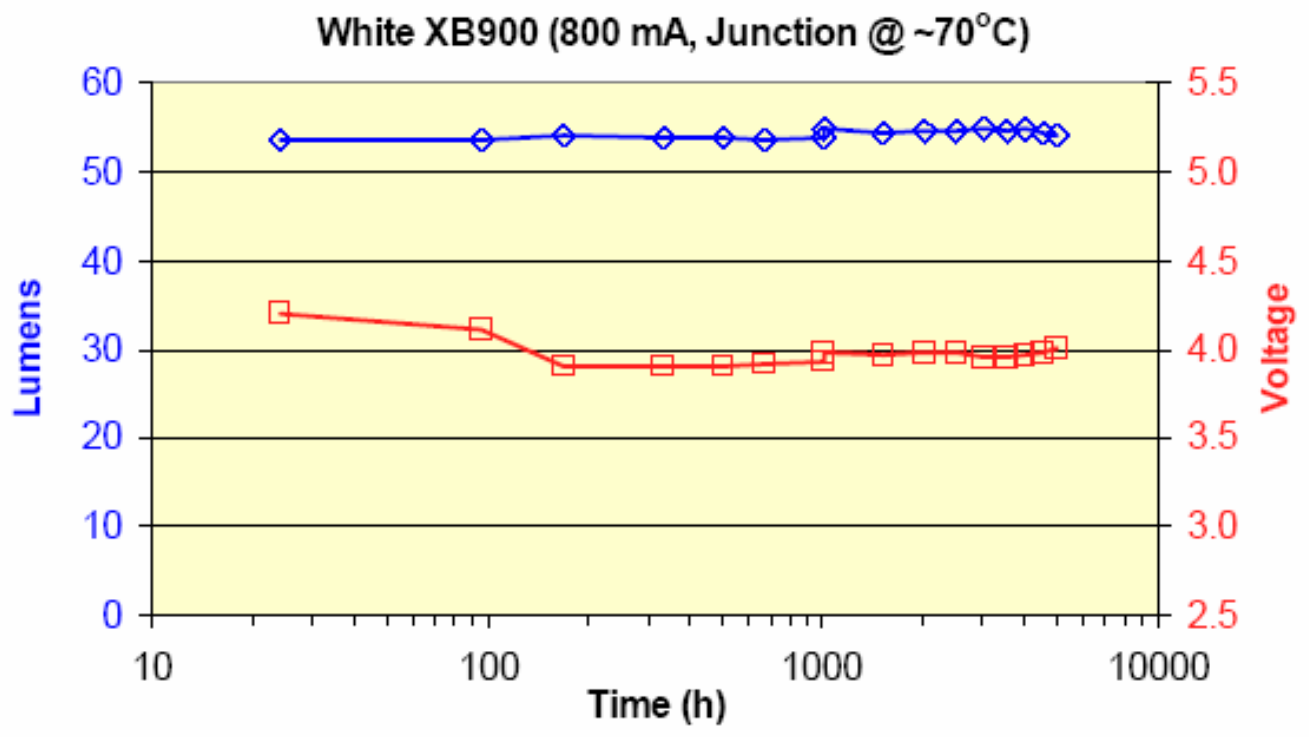

Figure 31: Average white LED flux and voltage maintenance. Drive current was $700 \mathrm{~mA}$. Ambient condition was room temperature, while the junction temperature was estimated to be $70^{\circ} \mathrm{C}$.

Figure 31 shows lifetime data for devices operating continuously at $800 \mathrm{~mA}$ up to 5000 hours, with the outcome that the target milestone was clearly met. The results were reproducible: two independent sets of lamps (different fabrication lots) showed almost identical behavior. It is also worth noting that individual lamps within each set behaved very similarly to each other and there were no catastrophic fails. Other key device parameters such as leakage current were also stable over the duration of the test.

Additional tests on blue and white lamps fabricated using the same set of blue chips and run at an elevated ambient temperature $\left(85^{\circ} \mathrm{C}\right.$ ambient, $\sim 135^{\circ} \mathrm{C}$ junction temperature) also showed almost no change in key device parameters up to 1000 hours (the duration of the test). A small difference observed between blue and white sets suggested the phosphor may have been degrading slightly at these elevated temperatures but the effect was small $(\sim 5 \%)$ and could have been an artifact of the relatively small sample set tested. 


\section{CONCLUSION}

In conclusion, novel chip designs and fabrication processes, together with improved materials work conducted outside this project, resulted in 1-watt class blue GaN/SiC LEDs with world record performance for comparable LEDs. In particular, the use of ray-trace modeling to identify areas to work on improved light extraction, in combination with efforts to verify the modeling results experimentally, proved to be a productive approach. As a result of this work, blue LEDs operating at $350 \mathrm{~mA}$ achieved $310 \mathrm{~mW}$ of light output, corresponding to quantum and wall plug efficiencies of $32.5 \%$ and $26.5 \%$, respectively. When combined with phosphor to create white light, the improved blue emitters also enabled the demonstration of white power LEDs with luminous output of 67 lumens and efficacy of 57 lumens per watt. Furthermore, from a purely commercial perspective the project's results in this area helped Cree to launch the first GaN/SiC power LED chip product family.

Despite the project's successes, when compared to the more mature arsenide-based (infra-red) and phosphide-bases (red/orange) LED technologies, where reported efficiencies have approached $60 \%$, the nitride-based LEDs demonstrated here clearly have room for further improvement. Indeed, this will be essential in order to reach white LED efficacy levels in the $>100$ lumens per watt range.

By scaling up the light output to levels comparable to conventional light sources through the use of compact arrays of LEDs, several of the key technology challenges for solid-state lighting were also identified and to some degree addressed under this project. In particular, the heat dissipation issue was addressed through the use of suitable package and chip attach materials. High power package concepts and packaging techniques were developed that enabled the demonstration of multi-chip LED modules possessing an overall junction-to-ambient thermal resistance as low as $1.7{ }^{\circ} \mathrm{C} /$ watt when mounted on a 2-inch square heat sink. At the same time, the critical importance of the heat sink was clearly demonstrated, which has implications for what may be achievable with solid state illumination sources in terms of their form factor (i.e. minimum size and weight) barring technology breakthroughs in this area.

System level optical losses were also shown to be manageable to a large degree, with less than $10 \%$ penalty demonstrated in a 16-chip module compared to single chip LED lamps. As a result, a 1000 lumens white lamp module was demonstrated with a luminous efficacy of 55 lumens per watt, or approximately three times that of a typical halogen incandescent lamp. However, the efficacy dropped to 40 lumens per watt in an LED-based MR16 prototype with 800 lumens output, based at least partly on additional optics incorporated in the design. Further work is needed to better understand the magnitude of the apparent trade-off between efficiency and optical beam control using LED-based lamps.

Finally, preliminary results confirmed the promise of very long (>>5000 hour) lifetime lamps based on high power (3-watt input) white LEDs when using appropriate materials in the construction of the LED lamps. Additional work is needed in this area to investigate the effect of operating junction temperature on lifetime, which ties in with the heat dissipation requirements of high flux lamps. 


\title{
Appendix A: Copy of Press Release Announcing Launch of Power Chip Product
}

\author{
FOR IMMEDIATE RELEASE \\ Contact: \\ Fran Barsky \\ Investor Relations Manager \\ Cree, Inc. \\ (T) $919-313-5397$ \\ (F) 919-313-5452 \\ email: fran_barsky@cree.com
}

\section{Cree Introduces New XBright ${ }^{\mathrm{TM}}$ Power Chip 10X Brightness Increase Over the Standard XBright Chip}

\begin{abstract}
Durham, NC, February 7, 2002 - At the Strategies In Light Conference taking place this week in San Francisco, California, Cree, Inc. (Nasdaq: CREE) is introducing its new XBright ${ }^{\mathrm{TM}} 900$ Power Chip light emitting diode (LED). At $900 \times 900$ microns, the LED XBright Power Chip is significantly larger than industry standard (300 $\times 300$ microns) LED chips and is the first large area version of the XBright technology LED chip offered by the company. The XBright 900 Power Chip product family includes an ultraviolet $405 \mathrm{~nm}$ device with a typical brightness of $250 \mathrm{~mW}$ at $350 \mathrm{~mA}$, and a $470 \mathrm{~nm}$ blue device with a typical brightness of 150 $\mathrm{mW}$ at $350 \mathrm{~mA}$. The targeted application for these devices is the specialty lighting market. The company has begun sampling devices with production targeted to ramp later this month.
\end{abstract}

Chuck Swoboda, President and Chief Executive Officer of Cree stated, "This is a tremendous milestone for Cree and for the industry. We believe that our new Power Chip sets a new standard for commercially available power chips in the market. Since these chips deliver more than 10 times the light output of our standard XBright chips, we believe these high power LED devices will enable a new range of lighting applications."

The XBright Power Chip product is an offshoot of a collaborative R\&D effort between Cree and the U.S. Department of Energy, National Energy Technology Laboratory (NETL).

Cree is an advanced semiconductor company that leverages its expertise in silicon carbide (SiC), gallium nitride (GaN) and silicon (Si) materials technology to produce new and enabling semiconductors. The products include blue, green and ultraviolet (UV) light emitting diodes (LEDs), near UV lasers, radio frequency (RF) and microwave devices, and power switching devices. Targeted applications for these products include solid state illumination, optical storage, wireless infrastructure and power switching. For more information on Cree, please visit www.cree.com.

This press release contains forward-looking statements involving risks and uncertainties that may cause actual results to differ materially from those indicated. Actual results could differ materially due to a number of factors, including the risk we may encounter delays or other difficulties in ramping up production of the new products, the risk the company will be unable to manufacture the products with sufficiently low cost to offer them at competitive prices or with acceptable margins, the potential lack of customer acceptance of the products; the risk of litigation asserting intellectual property claims; and other factors discussed in our filings with the Securities and Exchange Commission, including our report on Form 10-K for the year ended June 24, 2001 and subsequent reports filed with the Commission.

Cree and the Cree logo are registered trademarks, and XBright is a trademark of Cree, Inc. 


\title{
Appendix B: Copy of Press Release Announcing 74 lumen per watt R\&D Results
}

\author{
FOR IMMEDIATE RELEASE \\ Contact: Fran Barsky \\ Investor Relations Manager \\ Cree, Inc. \\ (T) 919-313-5397 \\ (F) 919-313-5615 \\ Fran_Barsky@cree.com
}

\section{CREE EXPANDS PRODUCT LINE WITH INTRODUCTION OF XTHIN ${ }^{\mathrm{TM}}$ LED PRODUCTS}

\section{Company Demonstrates 74 Lumens per Watt in R\&D Results}

Durham, NC, September 23, 2003 - Cree, Inc. (Nasdaq: CREE) today announced that it has begun volume production of its new XThin ${ }^{\text {TM }}$ light emitting diode (LED) products. Cree's XThin ${ }^{\text {TM }}$ LEDs are the next generation of solid-state LED emitters that combine highly efficient Group III nitride materials with Cree's silicon carbide substrate to deliver superior price performance for high intensity LEDs. These vertically structured LED chips are approximately 115 microns in height, representing over a 50\% reduction to our typical LED height, and have a lower forward voltage than our standard XBright $\circledast$ products. The geometrically enhanced epi-down design maximizes light extraction efficiency for improved white light conversion.

Mike Dunn, Vice President, Optoelectronics, stated, "We are excited to introduce our newest LED product with a lower forward voltage and a new thinner design which will enhance our XBright ${ }^{\circ}$ family of products. We believe that as we continue to add improvements to our chips, it will enable new opportunities in the marketplace for our LED products."

Target applications for this product include white LEDs for next generation mobile appliances for use in their LCD backlights and digital camera flash where brightness, sub-miniaturization, and low power consumption are required. For additional product specifications, please refer to the data sheets on Cree's website at www.cree.com under "LED Products."

In related news, Cree R\&D teams in Durham and at the company's Santa Barbara Technology Center have demonstrated a record $35 \%$ quantum efficiency at $20 \mathrm{~mA}$ for blue LEDs based on its XBright ${ }^{\circledR}$ chip technology. White LEDs fabricated using these novel XBright ${ }^{\circledR}$ chips produced 4.1 lumens of light in industry standard LED packages with an electrical energy conversion efficiency of 65 lumens per watt at $20 \mathrm{~mA}$. In laboratory packages the $X B$ right $(\AA$ chips produced 4.7 lumens of light with 74 lumens per watt. These are the highest known efficiencies publicly reported for LEDs emitting in the blue and white wavelength spectrum. This work was sponsored, in part, by the Department of Energy, Office of Energy Efficiency and Renewable Energy and by the State of California, California Technology Investment Partnership.

Cree is an advanced semiconductor company that leverages its expertise in silicon carbide (SiC), gallium nitride ( $\mathrm{GaN}$ ) and silicon ( $\mathrm{Si})$ materials technology to produce new and enabling semiconductors. The products include blue, green and ultraviolet (UV) light emitting diodes (LEDs), near UV lasers, radio frequency (RF) and microwave devices, and power switching devices. Potential applications for these products include solid-state illumination, optical storage, wireless infrastructure and power switching. For more information on Cree, please visit www.cree.com

This press release contains forward-looking statements involving risks and uncertainties, both known and unknown, that may cause actual results to differ materially from those indicated. Actual results may differ materially due to a number of factors, including the risk we may encounter delays or other difficulties in ramping up production of the new products; the risk we will be unable to manufacture the products with sufficiently low cost to offer them at competitive prices or with acceptable margins; the rapid development of new technology and competing products that may impair demand or render our products obsolete; the potential lack of customer acceptance for the products; and other factors discussed in Cree's filings with the Securities and Exchange Commission, including its report on Form 10-K for the year ended June 30, 2002 and subsequent quarterly reports.

Cree, the Cree logo and XBright are registered trademarks, and XThin is a trademark, of Cree, Inc. 